\title{
The Reflection of Income Segregation and Accessibility Cleavages in Sydney's House Prices
}

\author{
Matthew Ng, Josephine Roper, Christopher Pettit. Chyi-Lin Lee \\ July 2021
}

\begin{abstract}
This paper explores the relationships between accessibility, income segregation and house prices in the Greater Sydney Area. Sydney is found to have reasonably even employment accessibility, reflecting the increasingly polycentric nature of the modern city; however, it also shows considerable income segregation and variance in property prices between different parts of the city. Entropy is used to examine diversity and mixing of different income groups. Finally, hedonic price models using ordinary-least squareand geographically-weighted regression techniques to show the differing effects of employment accessibility on house prices in different parts of the city. The results show that accessibility has small to negative effects on prices in the most valuable areas, suggesting that other effects such as recreational access and employment type/quality may be important to investigate further in this context.
\end{abstract}

Accessibility; Geographically-weighted Regression; House Price; Gravity Models; Hedonic Price Models

\section{Introduction}

Accessibility is a multifaceted component of the built-environment. It is a measure that is linked to numerous distinct, but, related, urban dimensions such as, land-use, network structures, and population distribution (Miller 2018). Notionally, it is used to describe urban mobility within city systems, which include aspects of locational planning and facility distribution, equitable urban growth, as well as being used as a quantifiable metric for policy decisions (Páez et al. 2012, Masucci et al. 2013, Piovani et al. 2018, Yang et al. 2019). Its common inclusion in these dimensions reflects its nuance in representing complex urban processes into an interpretable metric across different geographies (Muraco 1972, Vickerman 1974). This is evidenced from the manifold studies that have now operationalised accessibility analyses to discuss issues of resource and infrastructure provision (Van Eck \& de Jong 1999), and land-use decision-making (Tsou et al. 2005, Sá et al. 2006, Cheng \& Bertolini 2013, Brondeel et al. 2014); to more systemic concerns of urban equity (Van Eck \& de Jong 1999, Curl et al. 
2011), social segregation (Massey \& Denton 1988, Arapoglou \& Sayas 2009, Li et al. 2013), and planning for alternative development futures (Cervero et al. 1997, Geurs et al. 2012).

Perhaps more fundamentally, given its reflection of more systemic urban issues, understanding accessibility thus provides an indispensable means to assess and interrogate policies of urban growth in a more substantiated way. Rightly so, stark disparities in accessibility imply an acute spatial mismatch of services, activities, and populations that may compound and enforce certain inequalities in cities (Kain 1992, Nelson \& Moore 1993, Ihlanfeldt 1994, Gobillon et al. 2007). Unequal accessibility also has tangible manifestations within a city's socioeconomic structures (Kain 1992). Thus far, a large body of literature has already established its disproportionate effect, not least, on low-income and ethnic groups (Kain 1992); but, also, on the provision of affordable housing (Hillier 2003, Dujardin \& Goffette-Nagot 2005); the reinforcement of poverty cycles (Gobillon et al. 2007, Åslund et al. 2010); and the differential outcomes of demographic groups that persist transgenerationally (Cervero et al. 1995).

Understanding the degree to which variations in accessibility are seen within cities, and the way they are spatially distributed forms this paper's main inquiry. In particular, it questions whether accessibility may relate also to variations in local income distribution and house prices. As property prices enumerates both individual property characteristics and locational attributes into a single figure, it may also be considered representative of an area's accessibility value (Mulley 2014, Pettit et al. 2020). With this, both incomes and property prices can be conceptualised as a component of a city's organisation. As such, it raises the question as to whether accessibility is considered in the valuation of more highly-priced areas; or, if so, whether high-accessibility areas remain exclusively for a more financially mobile demographic group.

Indeed, many studies have now demonstrated how the valuations indicatively adjust land and property prices to account the changing spatial distributions of urban facilities and activities (Bartholomew \& Ewing 2011, Proffitt et al. 2019). More recently, in Australia, work by Pettit et al. (2020) and Lieske et al. (2021) have spearheaded research endeavours in this domain. Both have highlighted the profound impact of policy and city infrastructure decisions on property values in the real world; and their work in enumerating the contributions of individual characteristics and neighbourhood variables to property values has had many implications on the use of quantifiable data to substantiate policymaking decisions. Similarly, earlier work by Mulley (2014) investigated the link between accessibility and transport modalities in creating property value changes in Sydney; however, it was found that proportionality in these variations were not uniform and were changeable across different locations.

In the same vein, this paper aims to expand the discourse through the addition of potential accessibility to employment as a variable that are complementary to those indicated by Pettit et al. (2020) and Mulley (2014). Here, employment accessibility within the Greater Sydney metropolitan is considered specifically, given its demonstrated links to economic productivity and upward mobility (Kain 1992, Cutler \& Glaeser 1997, Turner et al. 2009, Fan 2012, Knee- 
bone \& Holmes 2015). An important contribution for the analysis conducted in this paper is the consideration of the important dimension of social inequality by examining Sydney's neighbourhood income stratum, which may again be reflected directly in property values. Sydney is considered one of the most least affordable cities in the world (Bangura \& Lee 2019). Further, Randolph and Tice (2014) have found an increasing segregation in Greater Sydney. As such, this is important to have an enhanced understanding of the nexus between accessibility, income segregation, and house prices in an area given the paucity of existing research. Further, in the framework of the United Nations' goal of of achieving achieving more inclusive economic development in cities, as espoused in Sustainable Development Goal 11, understanding these dynamics may contribute more widely to more targeted housing policy and planning measures, as well as interventions.

\section{Accessibility, Income Segregation and House Prices}

The above section has briefly discussed he many effects of accessibility. Thematically, the discussion presented issues of persistent segregation, land-use constraints, and hurdles for upward mobility amongst disadvantaged demographic groups. These are a few themes noted most prominently in the existing literature (Geurs \& Van Wee 2004, Ferrer et al. 2018). Indeed, differential accessibility and its varied impacts on city form and function is important to understand for numerous reasons. It fundamentally upholds the established understanding that geographies are not homogeneous; and it argues that existing hyperlocal variations have far-reaching implications on both the structure of the urban system and the livelihood of its residents (Curl et al. 2011). Banister (2005) and Farrington (2007) noted that deft urban governance requires a granular appreciation of these hyperlocal variations to articulate the swathe of socioeconomic imbalances, arguably, brought on by decreased accessibility. They raise the idea of a 'poverty of access' as a tangible urban condition. Addressing this, therefore, is a key challenge for all levels of governance and city planning (Farrington 2007, p.324).

Central to this is the notion that poor accessibility comes in tandem with increased isolation. To this effect, it recognises that the variations in the spatial distribution of resources, essential amenities, and critical urban functions cause disparities that may work to simultaneously offer or restrict, opportunities (i.e., employment, education, healthcare, recreation) to specific population groups simply by virtue of their location (Davidson 1995, Ewing et al. 2002, Curl et al. 2011, Ewing et al. 2016). Consequently, differential costs are incurred across the urban system. For those groups found in low-accessibility areas, they are often disproportionately hampered through a multitude of costs, which include the increased financial expenditure of extended travel, in addition to critical losses in time- and opportunity- costs to overcome these shortfalls (Cutler \& Glaeser 
1997, Alesina et al. 1999, Alesina \& La Ferrara 2000, Charles 2003, Sánchez et al. 2011).

Wasmer \& Zenou (2002) highlighted differential costs are most apparent when low-accessibility is also coupled with lowered income. Taking the specific example of access to employment opportunities, it was found that the differential costs of movement incurred by segregated, low-income communities have the adverse effect of restricting the search for employment to more proximate areas, despite the availability of higher potential incomes further away (Wasmer \& Zenou 2002). Separating distances play a large role in these choices, as it was found that these demographic groups require greater ease to travel given the adhoc nature of their employment (Wasmer \& Zenou 2002). It is a phenomenon concurred with by Stoll (1999) and Giuliano \& Small (1993). The latter also reported that employing institutions often do not regard commuting distance as a barrier to workforce hires. Hence, it has been shown that there is typically no strong impetus to increase job proximity through the spatial redistribution of employment. Coupled with lowered-incomes, it becomes clear that the issue of poor-accessibility can be argued to be all the more punishing. Its prolonged effects in urban pockets signifies a persistence that often precedes the ghettoisation of lower-income earners (Cutler \& Glaeser 1997, De Bruyne \& Van Hove 2013).

The use of property values may be useful in examining these issues in finer detail. House prices plays an important role in contributing to the isolation of demographic groups (Määttänen \& Terviö 2014) — in that, where affordable housing is in a deficit, segregation is exacerbated and access into better serviced neighbourhoods becomes unattainable or difficult. Moreover, the increasing concentration of wealth that is accumulated from home ownership brings with it significant intergenerational benefits (Ohnishi et al. 2011). This has been argued to further reduce affordability in these urban pockets (De Bruyne \& Van Hove 2013). As such, with the disproportionate rise in wealth over time, the same issues of inequality are repeated. To this point, it is worth exploring whether house prices can be used as a proxy to determine both income and accessibility disparities within neighbourhoods. Indeed, few studies have investigated these specific relationships, despite being a long-standing item of debate (Davidson et al. 2018).

\subsection{Understanding Inequalities in Australia}

In 2018, the Australian Government's Productivity Commission released a report that examined inequality - with the distribution of income and wealth being most prominent - over a period between 1988 and 2016. The report concluded that inequality in Australia had only a marginal increase over the past three decades, as alleviated by Australia's sustained economic growth (AGPC 2018). It was further posited that significant growth was seen across all analysed socioeconomic groups; and with disparities seen at a reduced level in comparison to other developed nations (AGPC 2018). Since its release, however, reports have challenged these findings (Davidson et al. 2018, Sila \& Dugain 2019, Wiesel 
et al. 2020). They caution an oversimplification and a downplay of these disparities, which obscures the real complexity in the challenges of inequality faced by Australians.

In a more detailed representation of this inequality, Davidson et al. (2018) highlighted that the increase in disposable incomes within the country's highest earners has now reached a factor of over 25 in comparison to the lowest 5 per cent income bracket. In addition to this, income disparities were also noted to be more unequal than global metrics published by the Organisation for Economic Cooperation and Development (OECD) (Davidson et al. 2018). These denunciations come on top of those put forth by Gittins (2018), who established that poverty rates in Australia actually exhibited negligible improvements despite the growth in real incomes. With respect to this, it was reported that 40 per cent of Australia's lowest income earners depend on social welfare, in addition to low- full- and part- time employment (Davidson et al. 2018); whereas, in contrast, the build up of wealth in Australia's upper echelons of income earners more than quadrupled (Davidson 1995). It was proposed that a large part of these discrepancies was due to large increases in house prices driven by capital investments in the mid-2000s (Davidson et al. 2018, Wiesel et al. 2020). The result of which magnified wealth inequality in the country in a markedly disproportionate way as upper- and middle- class groups saw increases in wealth, in comparison to lower-income households that were found to have negligible gains in wealth (Gittins 2018).

Property again plays a significant role in this inequality. It was reported that Australia's highest socioeconomic groups hold, on average, approximately $\$ 1.95$ million in assets, in comparison to the $\$ 0.3$ million in lower income groups (Davidson et al. 2018). For higher income earners, 80 per cent of their wealth is comprised of properties as assets, with approximately 40 per cent attributed as a main residence, and an additional 12 per cent classed as investment real estate (Davidson 1995, Wiesel et al. 2020). These figures come in stark contrast to the 16 per cent average held by lower income groups on total property (Davidson et al. 2018).

It is clear from the findings above that the major role that property plays in the distribution of wealth in Australia requires further investigation. Perhaps what is most striking in the research undertaken by Davidson et al. (2018) is the extent to which lower-income households are dependent on part- and full- time employment, in comparison to more passive income streams available to those upper socioeconomic groups through real assets. It reiterates the importance for urban governance to be able to facilitate the required changes in policies to redress these inequalities. This requires governing bodies to understand local variations in access to jobs and area-level employment, in addition to how these factors spur socioeconomic segregation given their disproportionate importance to lower-income groups. This further allows more systemic issues on how the built-environment, in its current state, can be best shaped to uplift these communities. Certainly, these issues are all multifaceted and perhaps cannot be fully represented within any one urban metric; however, it forms the basis from which policies can be tested, interrogated, and revised to offer the best outcomes 


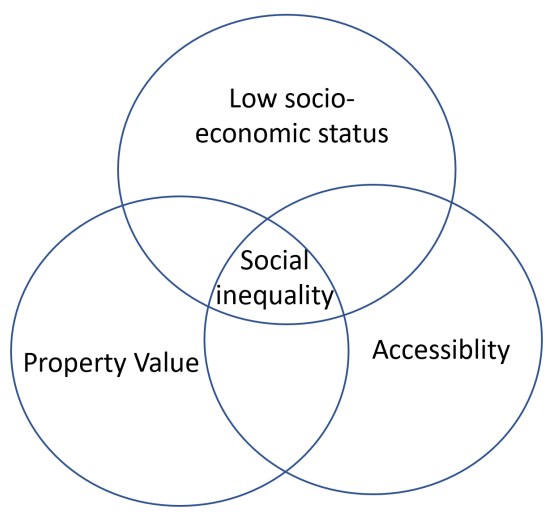

Figure 1: Proposed factors contributing to social inequality in Sydney

\section{Research Objectives}

The above discussions have now presented the theoretical framework (ref. Figure 1) around this paper's analysis of accessibility and income segregation. Three research aims can be formulated from this line of thought. First, the spatial distribution of income groups are quantified and visualised to highlight whether instances of income segregation are apparent. Here, entropy statistics are used as a measure of income diversity within areas; and their relationships to the relative proportion of different income groups are considered. Next, these income groups are analysed with respect to the spatial variations to employment accessibility in Sydney. As discussed above, poor accessibility is a barrier to upward mobility; therefore, determining their effects on lower-income groups is fundamental to achieving urban and social equity. Lastly, the above three variables are tested with respect to house prices in Greater Sydney to uncover where urban disparities manifest themselves with respect to residential property and their corresponding values.

\section{Data}

A number of datasets were used to examine above relationships. Table 1 provides a list of these datasets and their respective sources. These are expanded upon the relevant subsections with respect to their specific use as components in downstream analyses. 


\section{Dataset}

Road Network

Statistical Area 2 Neighbourhood Attributes

Journey to Work

Income Data

Geographic Statistical Boundaries

House Price

Points of Interest (including building footprints)

\section{Source}

OpenStreetMap

Australian Bureau of Statistics

Australian Bureau of Statistics

Australian Bureau of Statistics

Australian Bureau of Statistics

Australian Property Monitor

Geoscape Australia

Table 1: Table of datasets utilised and their sources

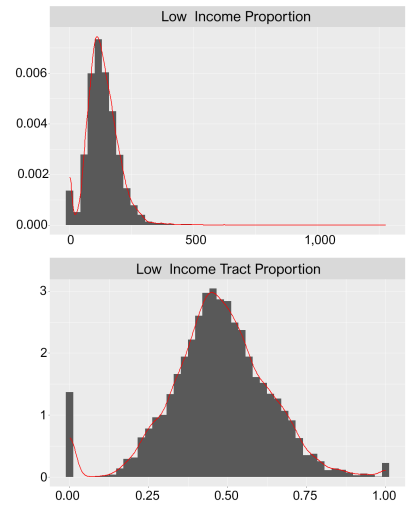

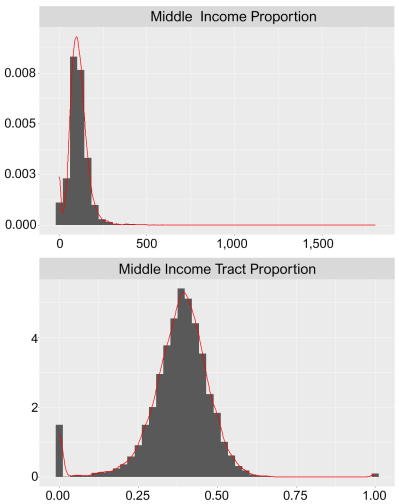
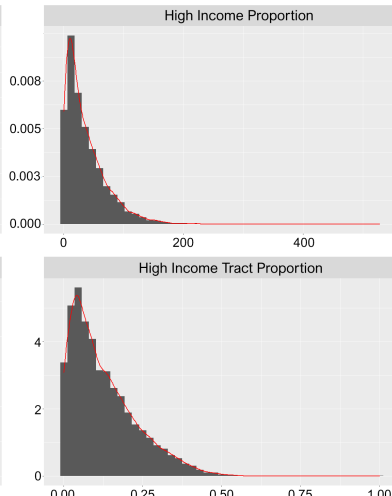

Figure 2: Distribution of income groups within the Australian Bureau of Statistics' Income Dataset

Census datasets from the Australian Bureau of Statistics (ABS), which include neighbourhood variables on median incomes and educational attainment, as well as employment and crime rates, were used. These neighbourhood indicators are available at both the Statistical Area 1 (SA1) and Statistical Area 2 (SA2) level from the ABS. SA1s, the primary level of analysis in this paper, are variable in size with a median population of 420 people, and area of $0.125 \mathrm{~km}^{2}$ in Greater Sydney. In addition to the above datasets, more granular data on personal income, and commuting flows were also obtained from the ABS. These form integral components to this study's accessibility modelling, and their use is discussed in the following subsections.

\subsubsection{Personal Income Data}

Income data for the 2016 census year was obtained at the SA1 level for the entirety of the Greater Sydney metropolitan area. The dataset refers to the ABS' Total Personal Income dataset, INCP, which collects the gross personal income received each week by an individual (ABS 2017). The data was filtered by an individual's place of usual residence to to reflect their residential 
locations. The INCP provided 17 income groups that ranged between $\$ 0$ to over $\$ 3000$ per week. These ranges were aggregated into three relative income groups, with income threshold adapted from the Australian Council of Social Services (ACOSS 2016) and the Property Council of Australia (PCA 2019). As such, low-income groups in this study are defined as individuals with a personal income of less than $\$ 649$ per week; middle-income groups ranged between $\$ 650$ to $\$ 1,999$ per week; and high-income groups were those with incomes above these thresholds. The distributions of these income ranges are illustrated in Figure 2. Both the total income groups and and their relative census tract proportions are taken into consideration. A total of 1.5 million low-income$\left(\bar{x}_{l \_ \text {tract }}=0.471\right), 1.3$ million middle-income- $\left(\bar{x}_{m_{-} \text {tract }}=0.376\right)$, and 0.4 million high-income- $\left(\bar{x}_{h_{-} \text {tract }}=0.153\right)$ individuals were enumerated in the dataset bringing the dataset size to 3.2 million individuals.

\subsubsection{Journey to Work}

Commuting data was also obtained for the 2016 census year from the ABS. This refers particularly to the Journey to Work dataset, which includes the recorded number of individuals reporting to from a SA1-level 'Place of Usual Residence' to a Destination Zone (DZN) level 'Place of Work'. DZN areas are constructed from mesh block boundaries, but are not considered a statistical boundary (ABS 2016). The dataset comprises reported population flows in the entire Greater Sydney Metropolitan area. 11,171 SA1 and 2,233 DZN entries were noted in the dataset. Approximately, 1.21 million persons are enumerated within this data with respect to their individual flows, which equated to approximately 25 million individual trips between all origin and destination zones. A cursory inspection of the Journey to Work dataset reveals that the Sydney City Centre and its surrounding appears to be the central locus of employment, with approximately 25 per cent of all flows. Other loci of employment with relatively high densities of population flow include Parramatta, North Sydney, Campbelltown, and Gosford. The distribution of flows show less variation across all other DZN areas.

The Journey to Work dataset was further extended to obtain both origin and destination capacities; and this can be derived from the sum of flows at both origin and destination zones. Their inputs within the developed accessibility model will be discussed in the subsequent section. The flow matrix was then restructured into a simple dataframe, which enabled the dataset to be joined by their respective zone codes to the appropriate SA1 and DZN boundary vectors. This data layer was segmented with proprietary vector data of house footprints obtained from Geoscape to identify the highest density cluster of houses within each delineated boundary. A median-weighted centroid was appended within each SA1 and DZN building cluster to obtain a single point for each origindestination zone (ref. Figure 3). 

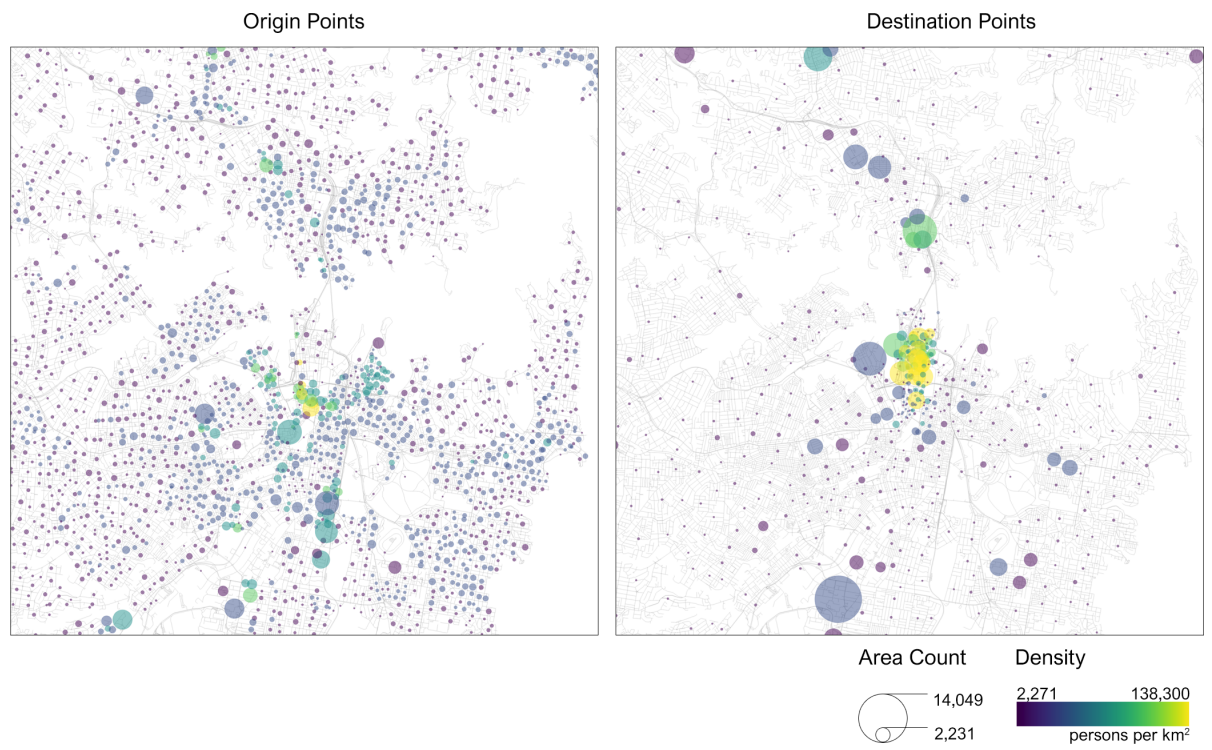

Figure 3: Example of origin and destination points centred on the CBD

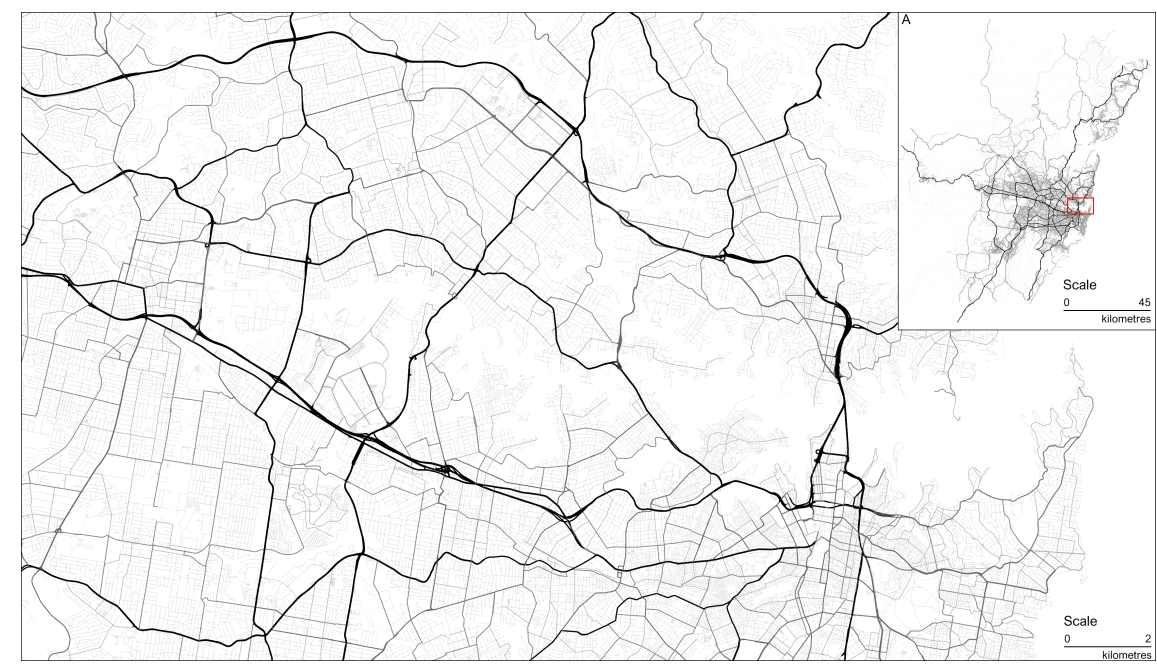

Figure 4: Cleaned Road Network

\subsection{Road Network}

The transportation network for the Greater Sydney region is from the GeoFabrik $^{1}$ repository of OpenStreetMap (OSM) features on $5^{\text {th }}$ August 2020. All OSM data layers within the Australian sub-region was selected, which included

${ }^{1}$ Site Available at http ://geofabrik.de/ 
a separate vector dataset of all transport lines in the region. The dataset was then processed in two stages to obtain a functional road network for Greater Sydney. First, a spatial subset of the data was created with boundary files obtained from the ABS. The vector boundaries were filtered by their individual region code attribute, ' $1 G S Y D$ ', to return only data of the Greater Sydney region. The full OSM transport network was clipped to this boundary to obtain all line features within Greater Sydney (ref. Figure 4). Next, the trimmed Greater Sydney transport network was then filtered through their attributes to obtain a network traversable by vehicles. These specific classes were defined from the metadata descriptions provided by Topf (2009). This process excluded line data for inappropriate transport modes such as bridleways, cycleways, and pedestrian only walkways. It should be noted that all unclassed transport links were also included in formation of the road network. The distribution of road type and the total road lengths can be found in Table 2.

\begin{tabular}{lrr} 
Classification & Line Count & Total Length $\mathbf{( k m )}$ \\
\hline Motorway & 11,220 & $2,466.10$ \\
Primary & 10,305 & $1,755.28$ \\
Residential & 178,668 & $23,203.15$ \\
Secondary & 16,705 & $2,537.34$ \\
Shared & 116 & 11.70 \\
Tertiary & 23,495 & $3,140.60$ \\
Tracks & 10,286 & $6,529.46$ \\
Unclassed & 8,716 & $2,363.12$ \\
\hline Total & $\mathbf{2 5 9 , 5 1 1}$ & $\mathbf{4 2 , 0 0 6 . 7 3}$
\end{tabular}

Table 2: Caption

The obtained road network was then processed to correct for any topological errors. This process involved the rectification of several error features, which included issues of excessive vertices, overlaps, self-intersections, pseudo-nodes, and disconnected road islands. In this study, all line intersections were accounted to obtain all possible edge features given the study's lack of ancillary data to correct for all possible continuous throughways. All errors arising from the above specification would be thus equally imposed throughout the entire network. To ensure the full connectivity of the obtained road network, a reiterative intersection detection algorithm was developed and implemented to obtain all possible edge connections. In this algorithm, all 'motorway' features were used to re-iteratively select all road intersections up to the boundaries of Greater Sydney. All unselected (i.e., disconnected road islands) clusters were discarded from the subsequent analysis. Figure 4 illustrates a small sub-region of the cleaned network.

The processed road network was subsequently used to calculate the separating network distance between each origin and destination point. This quantification represents the next major component to derive Greater Sydney's accessibility score. A network-based distance calculation was preferred over Euclidean distances due to the anisotropic nature of the built-environment. This is particularly pertinent for Greater Sydney as its physical environment includes 


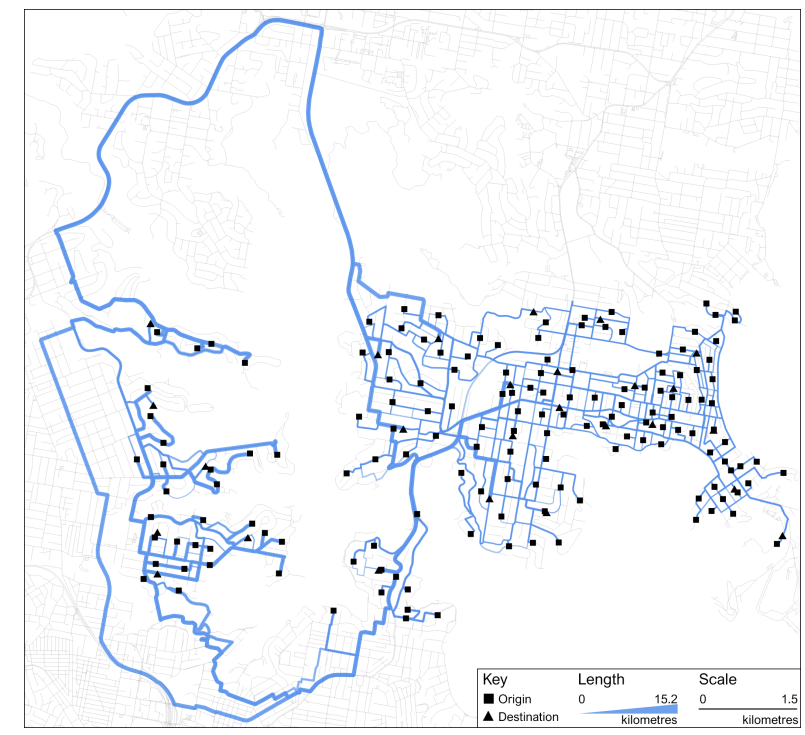

Figure 5: Illustrative depiction of the anisotropic nature of Sydney's road network

significant topological features that separate proximate areas. Figure 5 illustrates this point succinctly, with the water bodies of Sailors Bay and Peach Tree Bay viewed as strong separating features. It highlights the need to consider more realistic environmental features; and, in particular, their effect in augmenting the separation between origin-destination points through transport network availability.

\subsection{House Price}

The house price data used in this study was obtained from the Australian Property Monitor (APM). The data is comprised of over property sales between 1994 and 2020. The dataset set includes large number of individual variables for each property, with key information on the physical characteristics, temporal distribution of sales, and contract sale prices being particularly relevant to this study. This database comprised of approximately 1.82 million property sales ranging between 2006 and 2020. These sales data included both house and unit (also known as apartment) sales - from which, only houses were filtered out. Figure 6 illustrates the change of sale prices for houses over the the above time range. A subset of the house prices transacted in the two quarters of 2016 was used, which included 32,068 house price data points. This date range was chosen to coincide with the census data used.

The dataset was then processed in several rungs to negate issues of zeroinflation downstream; and to remove price outliers. Outliers in this study are defined as those prices that are $\leq 2.5$ per cent or $\geq 97.5$ per cent within the house price range. All property entries were then geocoded using the open data 


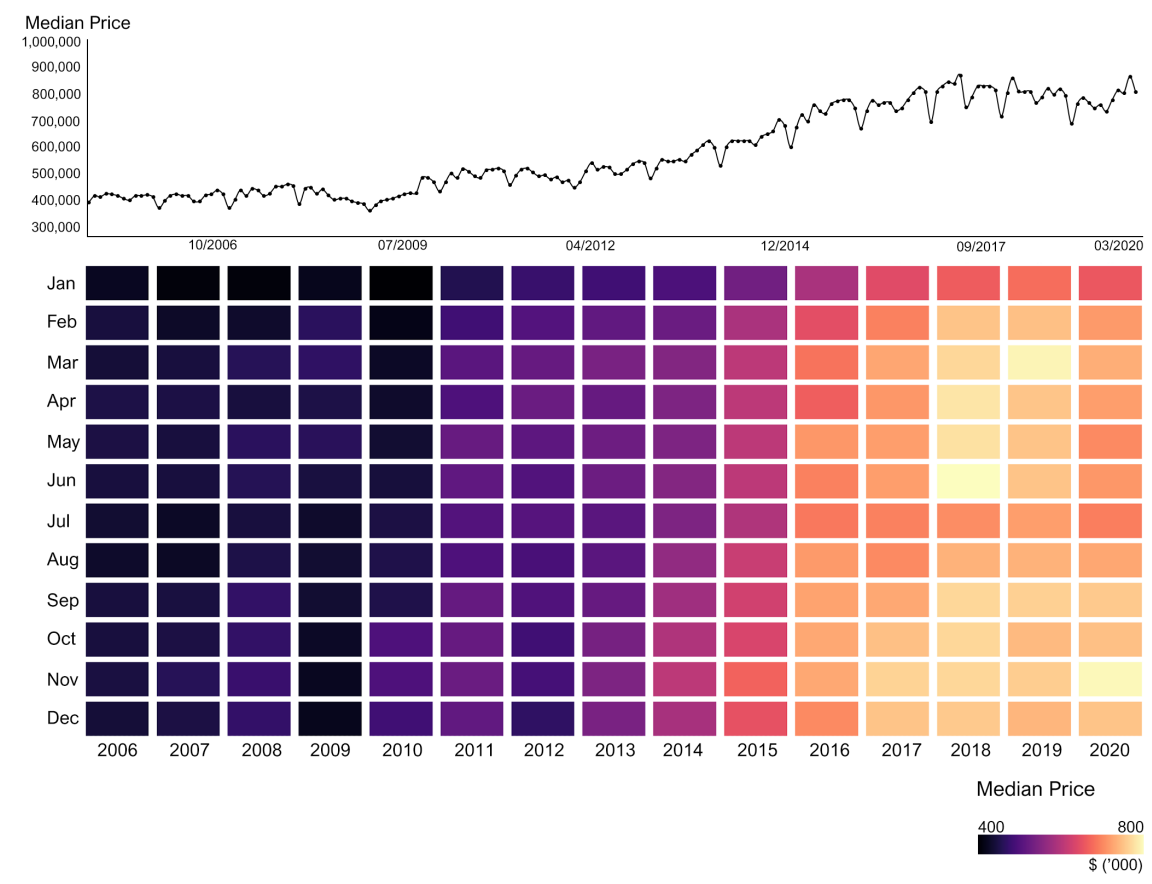

Figure 6: Temporal, count and price distribution of house prices from the Australian Property Monitor 3711 ,

Geocoded National Address File (G-NAF) available through Geoscape Australia.

\section{Methods}

\subsection{Entropy Measures}

Entropy values are widely used as a statistical measure to describe specific attribute compositions within the urban system (Batty et al. 2014). They are classically used to quantify disorder in an area; in which, high entropy values equate to large variances present within an area (Batty et al. 2014, Wilson 2013). Neighbourhood entropy is a robust indicator of spatial variance; and it is widely applied in land-use analyses, population composition, and economic activity (Tan \& Wu 2003, Wilson 2013). It is also considered within segregation analyses given its reflection of the heterogeneity of populations in localised areas (Fischer 2003). Following this logic, it offers a means to better understand diversity within a system. Here, the basic statistical form of entropy is adopted, and its application to income groups is implemented in this study.

The entropy measure utilised in this study can be represented by Equation 


$$
H_{i}=-\sum_{j=1}^{k} P_{i j} \cdot \ln \left(P_{i j}\right)
$$

... where, entropy $(H)$ at location $i$, is determined by the proportion of a specific income group, $j . K$ in the above equation refers to the number of income group types within the model. The proportion of this income group, $P_{i j}$, can be calculated with Equation 2,

$$
P_{i j}=\frac{N_{i j}}{\sum_{j=1}^{k} N_{i}}
$$

... with the tract total of an income group, $j$ in $N_{i j}$, is considered against the total of all income groups in the same tract, $N_{i}$. The maximum value of entropy $\left(H_{\max }\right)$ within a system is quantified with the following equation (ref. Equation 3).

$$
H_{\text {max }}=\ln (k)
$$

\subsection{Accessibility Indices}

This paper will consider accessibility as estimates derived from the gravity model (Hansen 1959), which can be expressed as Equation 4,

$$
T_{i j}=k \frac{V_{i}^{\mu} W_{j}^{\alpha}}{f\left(d_{i j}\right)}
$$

... where, the interaction $\left(T_{i j}\right)$ between zones $i$ and $j$ is determined by their respective 'mass' terms, $V_{i}$ and $W_{j} . k$ in the above equation refers the constant of proportionality as the interaction computed within the model is equal to the sum of their observed flows. $\alpha$ and $\mu$ are coefficients to be estimated. The 'mass' terms refer to known origin and destination specific attributes; and these may include variables such as total origin population or a factor for destination attractiveness (e.g., facility catchment (Luo 2014), total floorspace (Piovani et al. 2018), employment capacity (Kantorovich 1992, Hernández-Murillo \& Owyang 2006), or quality of facility (Geurs et al. 2015)). It can be argued that, in this instance, the gravity potential model provides a more nuanced proxy of accessibility in Greater Sydney, given the available population and flow data from the ABS. The models parameters and coefficients are computed in line with these datasets in the following way.

From the notation expressed in Equation 4, the gravity potential model can be alternatively written as, Equation 5,

$$
T_{i j}=k V_{i}^{\mu} W_{j}^{\alpha} d_{i j}^{\beta}
$$

... where, the flows $\left(T_{i j}\right)$ are derived in the same way from mass term and attraction factors noted at the origin $\left(V_{i}^{\mu}\right)$ and destination $\left(W_{j}^{\alpha}\right)$. It is worth reiterating that, the model is implemented using the JTW flows as $T_{i j}$; the total 
DZN density as $W_{j}^{\alpha}$; and the origin population total as $V_{i}^{\mu}$. Following Dennett's (2012) work, the natural log of each component within the model can thus be taken and respecified into in a log-linear format (ref. Equation 6):

$$
\ln T_{i j}=k+\mu \ln \left(V_{i}\right)+\alpha \ln \left(W_{j}\right)-\beta \ln \left(d_{i j}\right)
$$

... whereby, the model is considered as 'saturated' with all possible components to estimate potential flows. With this, the model can be fitted simultaneously to derive the necessary coefficients and factors for the relative attraction and emissivity of the origin and destination. However, considering the current specification, this study also implements a single production constraint to converge the model estimates accordingly to the origin totals $\left(O_{i}\right)$ as seen in Equation 7,

$$
\sum_{j} T_{i j}=O_{i}
$$

Consequently, this allows the accessibility model to be reshaped into Equation 8 ,

$$
\delta_{i j}=\exp \left(\sigma_{i}+\alpha \ln W_{j}-\beta \ln d_{i j}\right)
$$

... where, $\delta_{i j}$ refers to the observed flows; and $\sigma_{i}$ is taken as a categorical predictor for all flows in each origin SA1 (i.e., each individual SA1 code). Having now appropriately specified the model, the parameters for $\alpha$ and $\beta$ are solved for. The final parameter values used are 0.121 and -2.278 , respectively. With obtained parameters, the production-constrained model can be calculated as denoted by Wilson (1971) with the appropriate balancing factor, $A_{i}$. The preference for singly-constrained model over the attraction-production constraints is due to the unknown 'capacity' of employment within each DZN area; which, if constrained, would have been arbitrary. The calibration of the above parameters allows accessibility scores to computed with the classical gravity potential model (ref. Equation 4). The obtained values are then standardised between 1 and 0 for ease of interpretation.

The model performance is evaluated with the computed flow estimates against the observed flows. An acceptable $R^{2}$ of 0.61 was achieved, which suggests that the model is able to capture just over two-thirds of the employment flows occurring within Greater Sydney. It is also worth noting that the above models utilise a power law as its distance-decay function $\left(f\left(d_{i j}\right)=d_{i j}^{\beta}\right)$ over its exponential counterpart $\left(f\left(d_{i j}\right)=\exp ^{d_{i j} \beta}\right)$. Both functions were previously tested against the JTW observed flows; hence, the choice of the power-law function given its better results.

\subsection{Relationship Testing}

Having now considered the above data and models above, this study opted to conduct both an Ordinary Least Squares (OLS) regression and a Geographically Weighted Regression (GWR) to better understand their intrinsic relationships 
within the urban system. The OLS method is a global fitting method, which computes a single parameter estimates for each independent variable. However, given the spatial nature of the house price, income, and accessibility data, these relationships should also be tested with respect to their possible spatial variations. The model is derived from the traditional linear regression models; however, in its extension, the GWR includes a bandwidth parameter that considers a kernel of neighbouring points for each observation. Generally, the GWR model can be expressed as Equation 9,

$$
y_{i}=\beta_{0}\left(u_{i}, v_{i}\right)+\sum_{j} \beta_{k}\left(u_{i}, v_{i}\right) x_{i k}+\varepsilon_{i}
$$

... where the relationship between the dependent variable, $y_{i}$, and the set of independent variables, $j$, is represented by a continuous function $\beta_{k}\left(u_{i}, v_{i}\right)$ at different locations of $\left(u_{i}, v_{i}\right)$ at observation $i$. Here, the location of each data point is represented by coordinates $\left(u_{i}, v_{i}\right) ; \varepsilon_{i}$ represents the residual variable of the model. The GWR requires a bandwidth parameter, $b$, to be set, which are either fixed or adaptive (i.e., variable values of $b$ ) kernels. A spatial weights matrix is then constructed, with points closer to location $\left(u_{i}, v_{i}\right)$ assigned a higher value, and those exceeding the $b$ parameter are nullified. This can be generally expressed by Equation 10,

$$
w_{i j}= \begin{cases}1, & \text { if } d_{i j}<b \\ 0, & \text { otherwise }\end{cases}
$$

$\ldots$ where, $w_{i j}$ denotes the individual weights for each location of $\left(u_{i}, v_{i}\right)$; and $d_{i j}$ representing the distance threshold in consideration. It should be noted that the general expression for the above weights matrix is often altered through a weighting function, which is typically a gaussian or bi-square function (Fotheringham et al. 2003). In this paper, an adaptive bi-square was opted for due to its more sensitive allocation of weights with the increasing distances of all other data points (Fotheringham et al. 2003, Fotheringham \& Oshan 2016, Oshan et al. 2019). This function is denoted by Equation 11:

$$
w_{i j}= \begin{cases}\left(1-\left(\frac{d_{i j}}{b_{i(k)}}\right)^{2}\right)^{2}, & \text { if } d_{i j}<b_{i(k)} \\ 0, & \text { otherwise }\end{cases}
$$

In comparison to the general weights function where the $b$ represents a single integer, the $b_{i(k)}$ parameter here is variable with $k$ representing the number closest to point $i$ (Albuquerque et al. 2017). The optimum bandwidths are finally chosen through the minimisation of the Akaike Information Criterion (AIC) (Fotheringham et al. 2003, Fábián et al. 2014, Albuquerque et al. 2017).

\subsubsection{Multicollinearity Diagnosis}

The above house price dataset was then linked to neighbourhood and point of interest datasets based on house location. A test for multicollinearity was 
conducted to reduce the redundancy and imprecision in the regression model coefficient estimates arising from these variables. The diagnosis was approached by calculating the variance inflation factor (VIF) between each variable with respect to house prices. VIF accounts for the change in the independent variable coefficient estimate against any correlations between all independent variables within the model (Gareth et al. 2013). Gareth et al. (2013) noted that a VIF that exceed 10 is often considered problematic. The tolerance factor considers the likelihood of each independent variable being unaccounted for by all other independent variables within the model. Remedial measures to address the arising issues with multicollinearity include variable exclusions, principal component analyses, or step-wise regression applications (Bruce et al. 2020). This paper opted to exclude collinear variable pairs with an observed VIF scores greater than $10(V I F \geq 10)$.

\section{Results and Discussions}

\subsection{Income Distributions in Greater Sydney}

In response to this paper's first objective, the spatial distribution of income groups within the Greater Sydney area was considered. Entropy statistics $(H)$ were used as a measure to quantify the spatial diversity between these income. These values ranged from 0.00 to a maximum of $1.10\left(H_{\max }\right)$ - whereby, in areas where $H=1.10$, an equal distribution of all three income groups is observed. The global mean entropy value in Greater Sydney was calculated to be 0.862 , with a minimum and maximum of 0.00 and 1.09 , respectively.

\begin{tabular}{l|cccc} 
& Low Income & Middle Income & High Income & Entropy \\
\hline Low Income & 1.000 & -0.218 & -0.561 & -0.219 \\
Middle Income & -0.218 & 1.000 & 0.198 & 0.565 \\
High Income & -0.561 & 0.198 & 1.000 & 0.629 \\
Entropy & -0.219 & 0.565 & 0.629 & 1.000 \\
\hline
\end{tabular}

Table 3: Global correlation coefficients between income groups in Greater Sydney

Table 3 quantifies the correlation coefficients between all income groups and their respective entropy values. What is first noticeable is the negative relationship between the distribution of low-income groups in Sydney with their middle$(R=-0.22)$ and high- $(R=-0.56)$ income counterparts. This relationship is also seen with respect to entropy values $(R=-0.22)$. These findings come in stark contrast to those values associated with high- and middle- income earners, with both groups displaying similar correlation coefficients to the diversity index. These findings indicate that Sydney's income distribution appears to be highly asymmetric. Where it was initially thought that both high- and lowincome groups would both display exiguous mixing (i.e., low entropy scores in both high- and low- income groups), this generalisation can only be extended to the latter. The results rather show that high-income groups in Sydney ap- 
pear relatively more integrated at the metropolitan level, whereas low-income earners look to be concentrated in locations where those outside this income bracket remain unlikely to reside in.

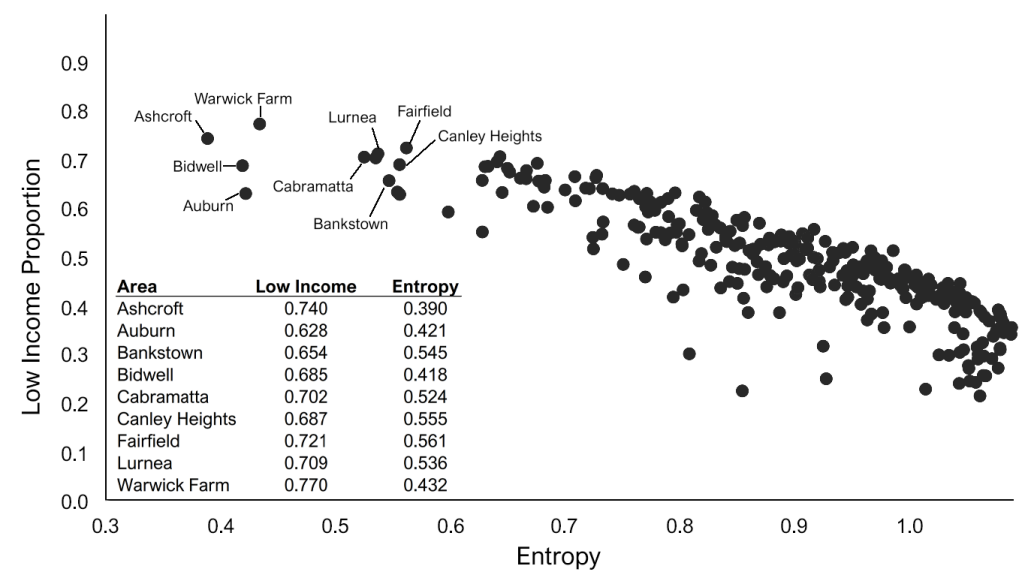

Figure 7: Entropy values against low-income groups in Greater Sydney

This more cursory evaluation does hint towards a possible degree of socioeconomic segregation in Greater Sydney; however, a disaggregated view of income distributions is needed to investigate whether the prominence of low-income groups is a consistent mainstay of areas of low-diversity. Figure 8 illustrates the spatial distribution of entropy and all income groups in view of this. It is evident from this visualisation that the spread of entropy values show a relatively clear delineation between low- and high- diversity areas, with lower entropy areas concentrated in the Central and Western suburbs of Greater Sydney, such as suburbs around Fairfield, Merrylands, Auburn, and Mount Druitt. In these areas, the diversity index is estimated to range between 0.39 to 0.55 ; and they also have the highest proportions of low-income earners in Greater Sydney (ref. Figure 7). Here, low-income groups constitute between 63 to 77 per cent of the population - often, with less than 2 per cent belonging to high-income groups (ref. Figure 7). The findings echo back to previous work by Lee et al. (2018), which empirically discussed the divide of the Sydney's demographic and socioeconomic distribution along a 'latte line'. It is interesting to note a similar divide is made apparent through the quantification of incomes.

When considered in line with the distribution of high-income groups, it is worth pondering on the reason these areas do not exhibit similar segregation seen with low-income areas. From the results displayed in Table 3, the distribution of high-income groups have already shown to be negatively correlated with the lowest earners $(R=-0.57)$ in Sydney, which alludes to the spatial division between both groups. However, it is interesting to note that, despite this disparity, high-income groups also occupy those areas with the highest entropy values. One explanation is due to the asymmetrical size of the different groups 


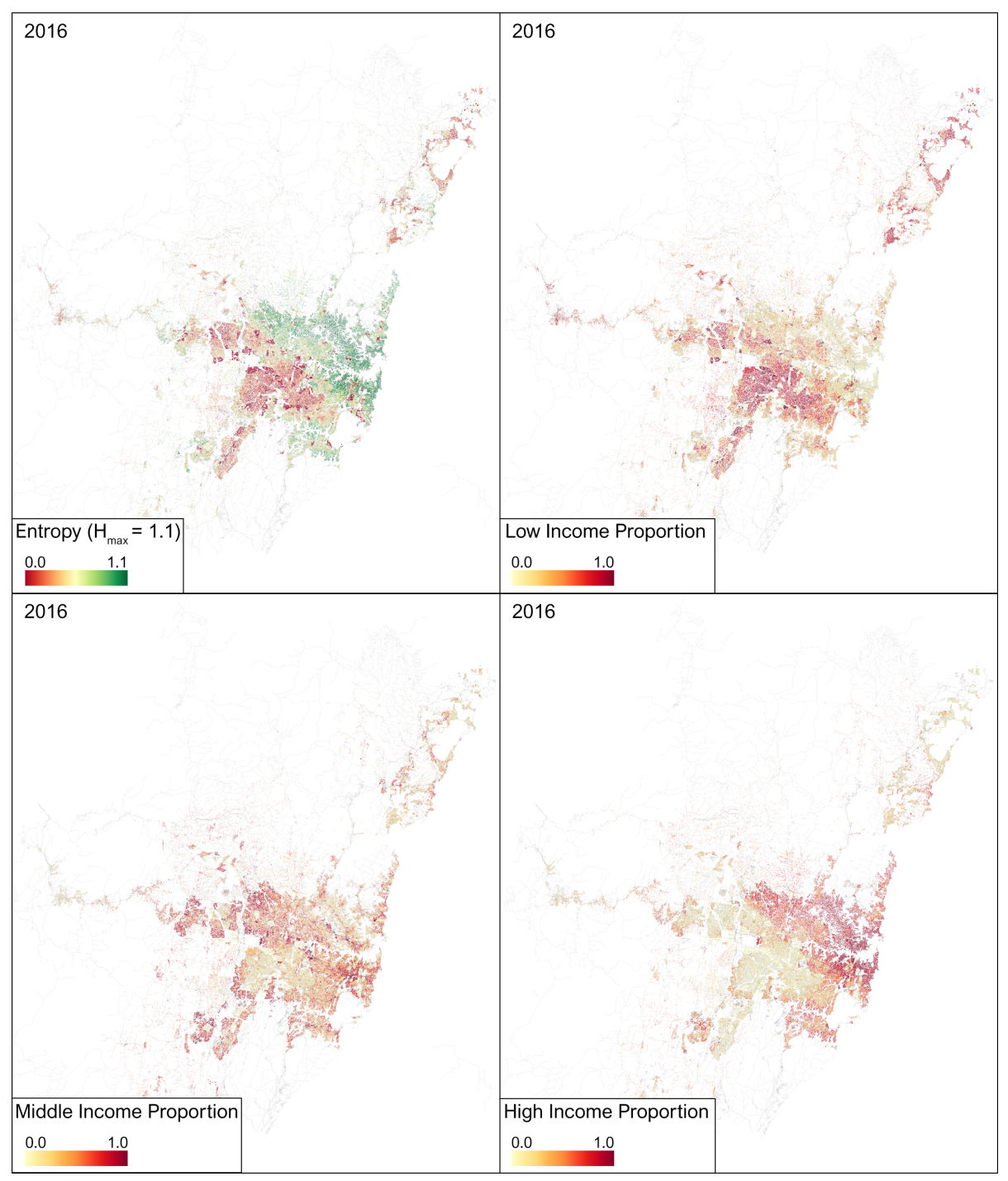

Figure 8: Entropy and income group distribution in 2016 


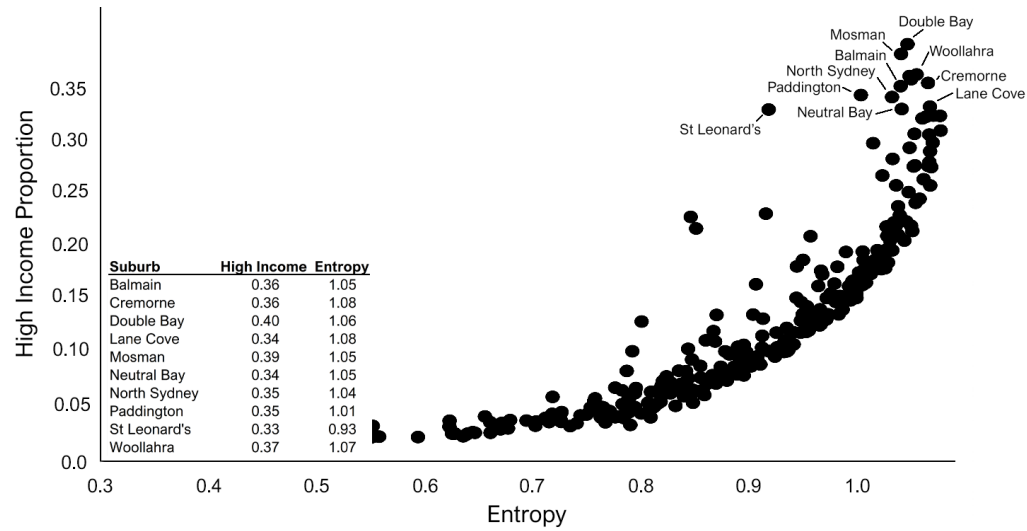

Figure 9: Entropy values against high-income groups in Greater Sydney

- as the high income group represents only 12 per cent of Sydney's population overall, even areas where they are heavily over-represented will still show considerable spatial overlap with the large group of middle-income earners, resulting in higher entropy values. For example, the highest $H$ values are found in areas that tend to be more proximate to the Sydney Central Business District and coastal suburbs such as Mosman, North Sydney, the Eastern Suburbs, and Manly. In these neighbourhoods, approximately 33 per cent to 40 per cent of the population fall within the high-income bracket (ref. Figure 9). Yet, they show a high entropy value, with the relative diversity being due to the spatial overlaps seen with middle-income earners $(R=0.57)$, who also tend to occupy these same areas. Further work on affordable housing is required to better understand if barriers to residency still exist; particularly, if ongoing developments only cater for demographic groups that are classified as middle-income earners. 


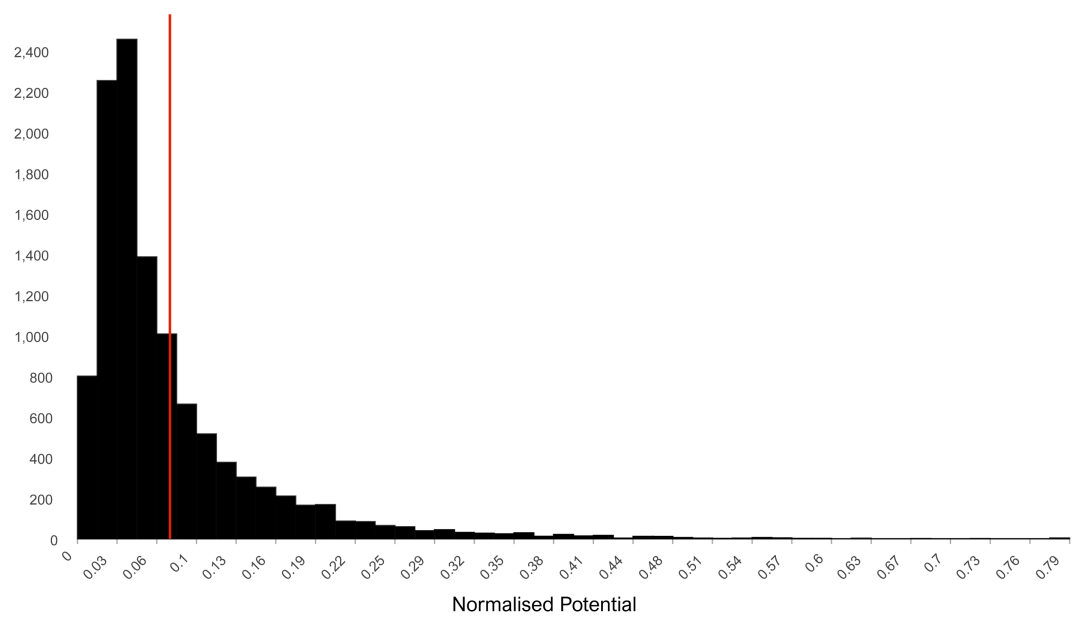

Figure 10: Distribution of computed potential accessibility scores to employments centres in Greater Sydney

The results above have now quantified the spatial delineation between income groups in Sydney. It has illustrated the possible sociospatial isolation that lower income groups may be confronted with given their distribution within Greater Sydney. As such, it raises the concerns as to whether these income groups may disproportionately experience the same negative spatial externalities seen in many cities globally. This paper thus seeks to now investigate whether any variances in accessibility are observed in line with Greater Sydney's observed income spread. The distribution of accessibility scores, computed from the gravity potential model, are displayed in Figure 10. The normalised potential accessibility score was estimated to range between 0.01 to 0.78 , with a mean score of 0.07 . The highest potential scores were noted in those suburbs within- and proximate to- Sydney's Inner City, North Sydney, Mascot, Macquarie Park, Epping, Chatswood, and Parramatta. These areas hold the highest employment densities concentrating approximately 40 per cent of all within the Greater Sydney area. Model estimates indicate that the Sydney Inner City area constitutes approximately 22.5 per cent of all metropolitan employment movement. This is a figure also reflected in the JTW census data, in which the area recorded a 22.7 per cent share of Sydney's total working population in 2016.

Conversely, it is interesting to note that the spatial distribution of lower potential accessibility scores appears relatively evenly throughout many suburbs across the Greater Sydney region. The median potential score of these areas is estimated to be approximately 0.04 . This potential score comes despite a relatively substantial number of smaller employment loci available (e.g., in Ashfield, Burwood, Balgowlah, Canterbury, Kogarah, Marrickville) within these largely 

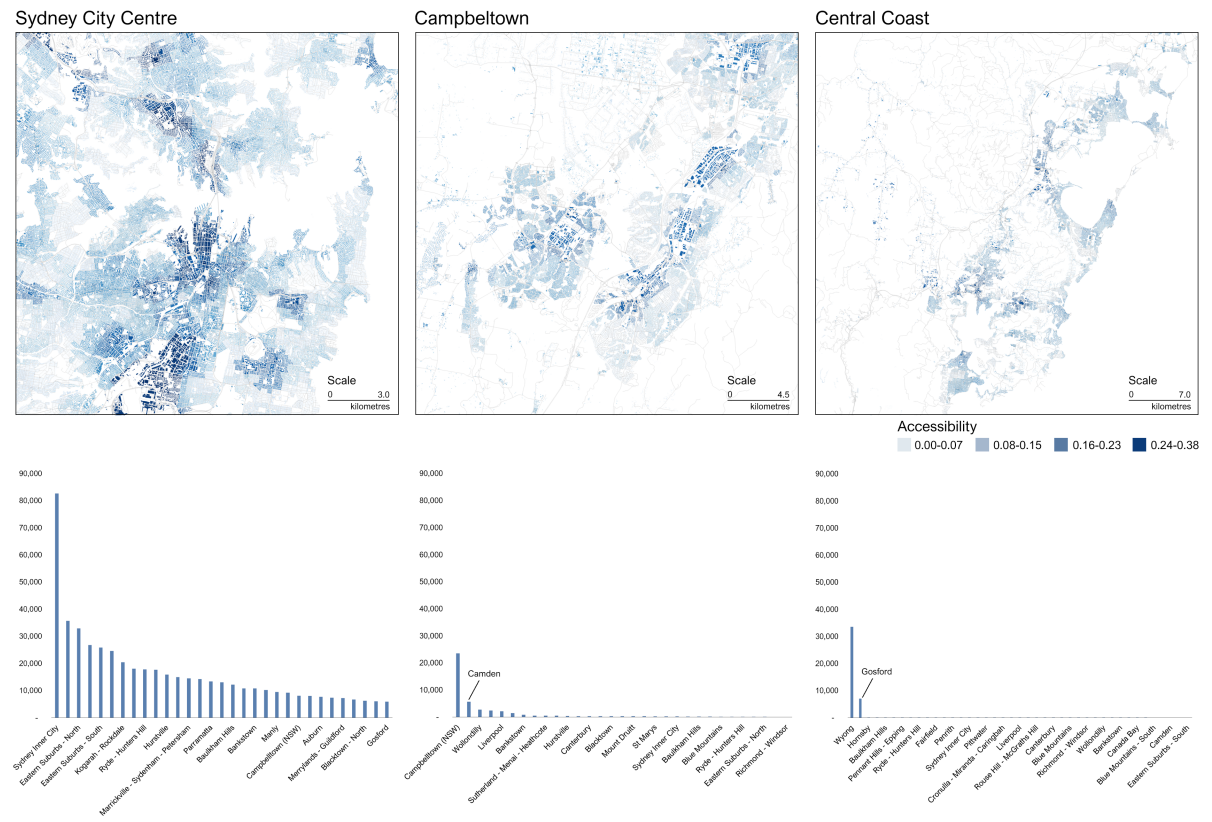

Figure 11: Sources of employment flows for major employment clusters

suburban areas. The findings suggest that, despite these smaller pockets of employment, the Sydney City Centre, North Sydney, Macquarie Park, Parramatta, and Chatswood remain the most significant employment clusters within the Greater Sydney system. Several exceptions to this are noted within the Greater Sydney periphery however. In more distal areas, such as Katoomba, Campbelltown, and Gosford, potential accessibility scores also remain relatively high. This deviation is likely attributed to large intervening distances between these areas to Sydney's primary employment hubs. As a result, these areas appear to have a secondary role in centralising employment flows within Sydney, particularly at the metropolitan's periphery. This centralising pattern of movement is also captured within the accessibility model's estimated flows. For example, between Sydney City and Campbelltown, there is a clear distinction between the source of movement within both these locations (ref. Figure 11). Where Sydney City sees movement from all suburbs across Greater Sydney; within Campbelltown, model estimates indicate predominantly inter-zonal movement, with more modest population flows from Camden, Liverpool, and Bankstown. In contrast to these flows, peripheral zones, such as the Central Coast, form a separate employment locus given this distance. In these areas, accessibility remains relatively high given that employment flows are seen to be almost exclusively circumscribed to within the region (ref. Figure 11).

Considering these flow trends in line with the spatial variances in accessibility, attention should be drawn to those intermediary zones that fall in between 


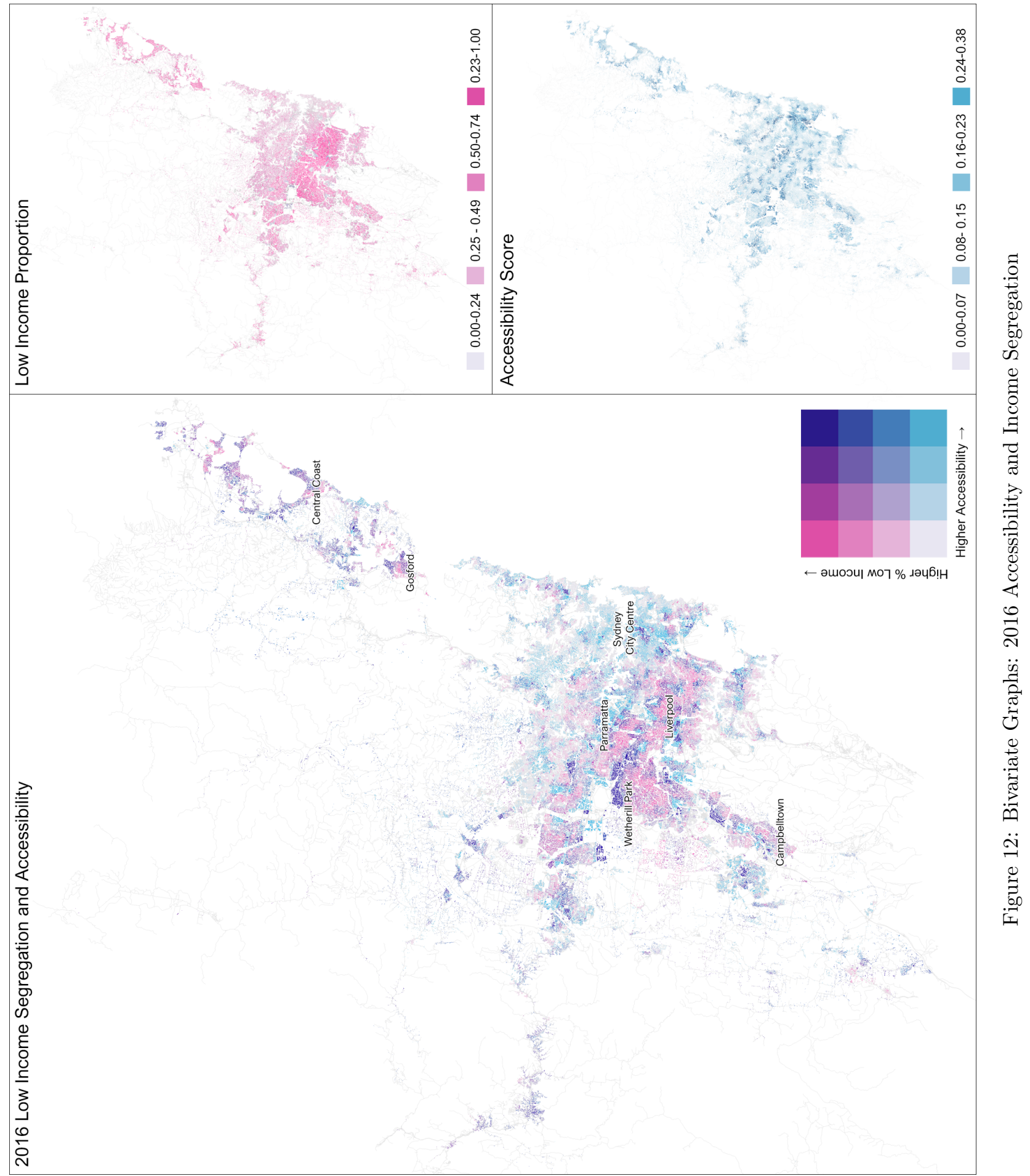


Sydney's major employment hubs where low accessibility is noted throughout. These areas are typified by low-density, residential land-uses. The greater topological distances to Greater Sydney's employment centres draws attention to the disparate costs that may be experienced by resident populations; thus, it reiterates the need to better understand these accessibility costs in view of their socioeconomic structures. Figure 12 illustrates the distribution of accessibility scores relative to that of low-income groups. It is interesting to note that, whilst low-income groups can generally be delineated within Sydney's inner South, Southwest, and Blacktown-area suburbs, there does not appear to be any clear correlation in accessibility variances within these areas $\left(R^{2}=0.01\right)$. Therefore, the findings cannot support previous assumptions of socioeconomic stratification and isolation due to accessibility variance.

In this sense, employment accessibility appears to be experienced equally across income groups within Sydney. However, at this juncture, it is worth repeating that employment density is taken as a proxy to employment area attractiveness. Certainly, whilst this does look to be a relatively useful measure of Sydney's employment movement, no measure of employment type- or qualityhas been taken into account within the current accessibility model. It is also worth repeating that accessibility in Sydney has been shown to be pervasively low throughout the greater metropolitan area, with the exception of those areas adjacent to Sydney City, Chatswood, and Parramatta. As such, whilst no spatial disadvantages can be attributed to lower-income areas in this study, further work is required to ascertain whether these disadvantages are seen perhaps in the quality and type of employment.

\section{House Values, Accessibility, and Income Seg- regation in Sydney}

Having now considered the relationship between income groups and accessibility, this paper now shifts its focus towards understanding if these variables may also be alternatively reflected in house prices. First, an OLS regression was conducted to understand how house prices may be affected by these variables within the entire system. The results of the test is indicated in Table 4 . The model performance indicates a multiple- and adjusted- $R^{2}$ value of 0.81 for both, which indicates a fairly strong linear relationship across all variables whereby over 80 per cent of the model variances (normalised through a logarithmic transformation) can be accounted for by the independent variables. For the most part, the results of the OLS model indicate a fairly predictable relationship between house prices and the independent variables used. House prices are noted to markedly increase with size. This was proxied by the number of bedrooms, bathrooms, and parking spaces, as well as increasing distances from major infrastructure features and major recreational sport facilities. This comes in addition to the negligible increases in house prices are also seen with increasing distances from educational facilities, and shopping centres. As also expected, negative changes in house prices are also linked to increased distance from Sydney City, beaches, 
635

Residuals:

$\begin{array}{ccccc}\text { Min } & \text { 1Q } & \text { Median } & \text { 3Q } & \text { Max } \\ -3.08558 & -0.14556 & -0.01844 & 0.11633 & 2.40827\end{array}$

Coefficients:

\begin{tabular}{|c|c|c|c|c|c|}
\hline & Estimate & Std. Error & t-value & $\operatorname{Pr}(>|\mathbf{t}|)$ & \\
\hline (Intercept) & $1.33 \mathrm{E}+01$ & 5.69E-02 & 233.182 & $<2.00 \mathrm{E}-6$ & $* * *$ \\
\hline Bedrooms & $1.42 \mathrm{E}-01$ & $1.58 \mathrm{E}-03$ & 90.152 & $<2.00 \mathrm{E}-6$ & $* * *$ \\
\hline Bathrooms & 4.89E-02 & $1.48 \mathrm{E}-03$ & 33.016 & $<2.00 \mathrm{E}-6$ & $* * *$ \\
\hline Distance to Sydney & $-1.45 \mathrm{E}-05$ & 1.69E-07 & -85.66 & $<2.00 \mathrm{E}-6$ & $* * *$ \\
\hline Distance to Secondary City & 7.07E-07 & $1.74 \mathrm{E}-07$ & 4.065 & $4.82 \mathrm{E}-05$ & $* * *$ \\
\hline Distance to Beach & $-2.44 \mathrm{E}-06$ & $2.24 \mathrm{E}-07$ & -10.916 & $<2.00 \mathrm{E}-6$ & $* * *$ \\
\hline Distance to Bus Interchanges & $2.91 \mathrm{E}-06$ & 4.83E-07 & 6.031 & $1.65 \mathrm{E}-09$ & $* * *$ \\
\hline Distance to Highway & 7.50E-06 & 4.44E-07 & 16.883 & $<2.00 \mathrm{E}-6$ & $* * *$ \\
\hline Distance to Primary School & 1.02E-05 & $3.26 \mathrm{E}-06$ & 3.118 & 0.00182 & $* *$ \\
\hline Distance to University & $1.12 \mathrm{E}-06$ & 4.27E-07 & 2.617 & 0.00889 & $* *$ \\
\hline Distance to Swimming Pool & $-4.61 \mathrm{E}-06$ & $9.32 \mathrm{E}-07$ & -4.952 & $7.40 \mathrm{E}-07$ & $* * *$ \\
\hline Distance to Shopping Centre & $1.11 \mathrm{E}-05$ & $7.50 \mathrm{E}-07$ & 14.774 & $<2.00 \mathrm{E}-6$ & $* * *$ \\
\hline Distance to Sport Centre & $9.00 \mathrm{E}-06$ & 7.27E-07 & 12.378 & $<2.00 \mathrm{E}-6$ & $* * *$ \\
\hline Population Above 65 (\%) & 5.08E-03 & 2.17E-04 & 23.355 & $<2.00 \mathrm{E}-6$ & $* * *$ \\
\hline Crime Rate (\%) & $-4.35 \mathrm{E}-02$ & 1.62E-02 & -2.681 & 0.00735 & $* *$ \\
\hline Low Income (\%) & $-1.87 \mathrm{E}-01$ & $5.75 \mathrm{E}-02$ & -3.244 & 0.00118 & $* *$ \\
\hline Middle Income (\%) & $-1.02 \mathrm{E}-01$ & $5.80 \mathrm{E}-02$ & -1.758 & 0.0788 & . \\
\hline High Income (\%) & $2.51 \mathrm{E}+00$ & $5.97 \mathrm{E}-02$ & 41.983 & $<2.00 \mathrm{E}-6$ & $* * *$ \\
\hline Accessibility Score & 2.73E-01 & 8.68E-02 & 3.142 & 0.00168 & $* *$ \\
\hline
\end{tabular}

Significance Codes:

Number of data points: 32,050

$$
0^{\text {‘***) }} 0.001 \text { '**) } 0.01 \text { '*, } 0.05 \text { '? } 0.1 \text { ' } 1
$$

Residual standard error: 0.2455 on 32,049 degrees of freedom

Multiple R-squared: 0.8103, Adjusted R-squared: 0.8102

F-statistic: 7,604 on 18 and 32,049 DF, p-value: <2.2e-16

Residual sum of squares: 1,931.751

$A I C:$ 952.1797

AICc: 952.2059

Table 4: Coefficient values derived from the OLS regression of variables to house prices

However, in view of this study, it is interesting to note the differences in significance levels both income groups and accessibility scores display on house prices. The OLS model indicates that the presence of both low- and highincome groups are relatively sound predictors for the variance in house prices in Greater Sydney, with the model indicating a significance level of at least 99 per cent. Accessibility scores also look be significant at the global level, with a $p$-value of less than 0.01. As denoted within the model, increasing proportions of low- and high- income groups display a relative change of -0.2 and 2.5 per cent change in house price, respectively. Further, at the metropolitan level, relative rise of 0.3 per cent is with house prices within areas that have increased accessibility. It is worth noting that the presence of middle-income groups, as defined in this study, do not indicate the same level of predictive potential. This is likely due to their larger aggregation of income into a single group; and 
esulting relatively even distribution throughout all of Greater Sydney.

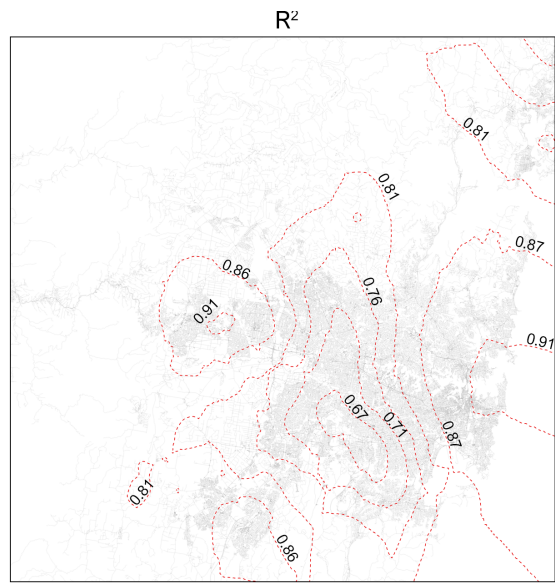

High-Income

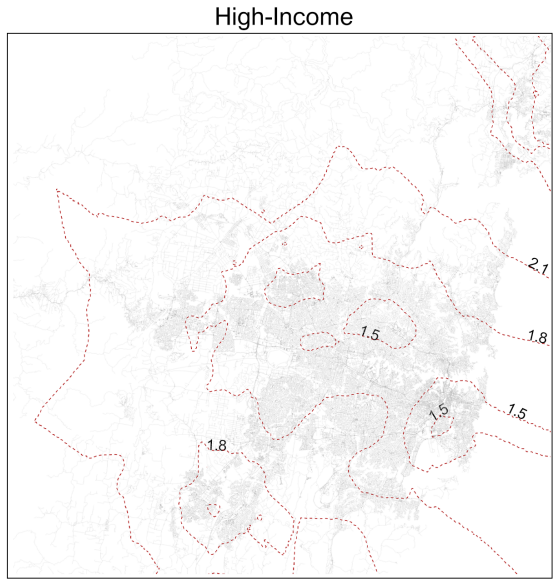

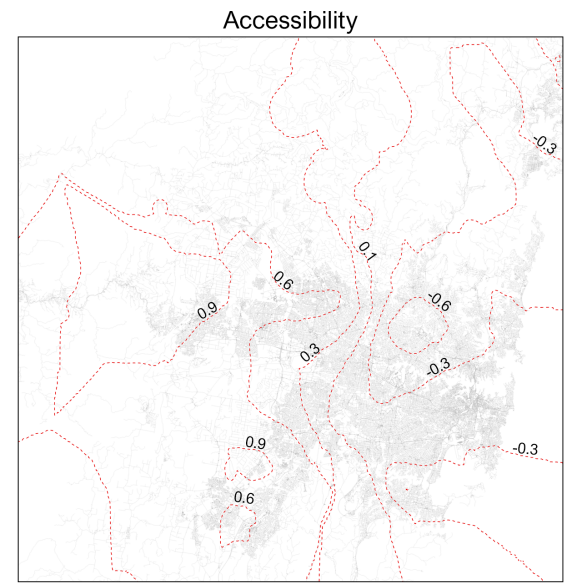

Low-Income

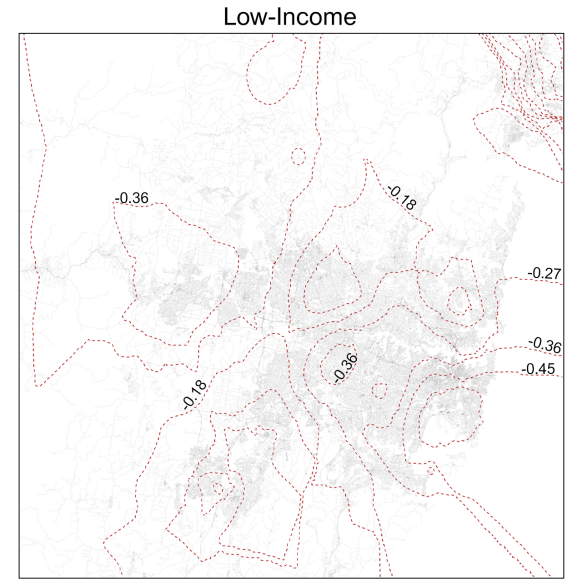

Figure 13: Contour visualisation of income and accessibility coefficients throughout Greater Sydney

Nevertheless, whilst the OLS model provides a relatively sound representation of house price variances at the metropolitan level, their local effects also need to be considered with respect to the spatial non-stationarity of property. These local effects are considered within the subsequent GWR model. The GWR model specified here indicates an improvement in performance, with a adjusted $R^{2}$ value of 0.844 and a lowered residual sum of squares value of 1,569 . The spatial distribution of the local $R^{2}$ values, along with the coefficient estimates for accessibility, high- and low- income groups, is illustrated in Figure 13. The GWR model performance tends to remain high, with at least 67 per cent of house price variances accounted for across all of Greater Sydney.

A summary of the model's coefficient estimates is also provided in Table 5. The findings here provide a more granular estimate of the model's income 


\begin{tabular}{|c|c|c|c|c|c|}
\hline ummary of GWR coefficien & $\begin{array}{l}\text { nates: } \\
\text { Min }\end{array}$ & 1Q & Median & 3Q & $\operatorname{Max}$ \\
\hline Intercept & $6.2 \mathrm{E}+00$ & $1.3 \mathrm{E}+01$ & $1.4 \mathrm{E}+01$ & $1.4 \mathrm{E}+01$ & $1.8 \mathrm{E}+01$ \\
\hline Bedrooms & $1.1 \mathrm{E}-01$ & $1.2 \mathrm{E}-01$ & $1.4 \mathrm{E}-01$ & $1.6 \mathrm{E}-01$ & $1.9 \mathrm{E}-01$ \\
\hline Bathrooms & $2.8 \mathrm{E}-02$ & 4.0E-02 & $5.1 \mathrm{E}-02$ & $5.8 \mathrm{E}-02$ & $8.1 \mathrm{E}-02$ \\
\hline Distance to Sydney & $-3.4 \mathrm{E}-05$ & $-3.0 \mathrm{E}-05$ & $-2.3 \mathrm{E}-05$ & $-1.5 \mathrm{E}-05$ & $0.0 \mathrm{E}+00$ \\
\hline Distance to Secondary City & $-1.6 \mathrm{E}-05$ & $-4.7 \mathrm{E}-06$ & $-5.6 \mathrm{E}-07$ & $4.1 \mathrm{E}-06$ & $0.0 \mathrm{E}+00$ \\
\hline Distance to Beach & $-3.8 \mathrm{E}-05$ & $-8.7 \mathrm{E}-06$ & $2.3 \mathrm{E}-06$ & $8.7 \mathrm{E}-06$ & $0.0 \mathrm{E}+00$ \\
\hline Distance to Bus Interchanges & $-3.8 \mathrm{E}-05$ & $-9.7 \mathrm{E}-06$ & $-3.2 \mathrm{E}-06$ & $4.4 \mathrm{E}-06$ & $0.0 \mathrm{E}+00$ \\
\hline Distance to Highway & $-1.8 \mathrm{E}-05$ & 3.0E-06 & 7.6E-06 & $1.1 \mathrm{E}-05$ & $0.0 \mathrm{E}+00$ \\
\hline Distance to Primary School & $-3.7 \mathrm{E}-05$ & $1.3 \mathrm{E}-05$ & $2.7 \mathrm{E}-05$ & $4.5 \mathrm{E}-05$ & $1.0 \mathrm{E}-04$ \\
\hline Distance to University & $-2.1 \mathrm{E}-05$ & $2.3 \mathrm{E}-06$ & $6.5 \mathrm{E}-06$ & $1.1 \mathrm{E}-05$ & $0.0 \mathrm{E}+00$ \\
\hline Distance to Swimming Pool & $-2.7 \mathrm{E}-05$ & $-1.3 \mathrm{E}-05$ & $-4.5 \mathrm{E}-06$ & $6.8 \mathrm{E}-06$ & $0.0 \mathrm{E}+00$ \\
\hline Distance to Shopping Centres & $-1.5 \mathrm{E}-05$ & $-4.0 \mathrm{E}-07$ & $7.2 \mathrm{E}-06$ & $1.8 \mathrm{E}-05$ & $0.0 \mathrm{E}+00$ \\
\hline Distance to Sports Centres & $-1.2 \mathrm{E}-05$ & $3.6 \mathrm{E}-06$ & $6.7 \mathrm{E}-06$ & $1.4 \mathrm{E}-05$ & $0.0 \mathrm{E}+00$ \\
\hline Population Above 65 & $1.2 \mathrm{E}-03$ & $2.6 \mathrm{E}-03$ & 3.7E-03 & $5.8 \mathrm{E}-03$ & 8.9E-03 \\
\hline Crime Rate & $-3.1 \mathrm{E}-01$ & $-8.0 \mathrm{E}-02$ & $-2.1 \mathrm{E}-02$ & $1.0 \mathrm{E}-01$ & $6.8 \mathrm{E}-01$ \\
\hline Low Income (\%) & $-7.2 \mathrm{E}+00$ & $-3.8 \mathrm{E}-01$ & $-2.8 \mathrm{E}-01$ & $-1.6 \mathrm{E}-01$ & $5.0 \mathrm{E}+00$ \\
\hline Middle Income (\%) & $-6.6 \mathrm{E}+00$ & $-3.1 \mathrm{E}-01$ & $-1.8 \mathrm{E}-01$ & $-6.7 \mathrm{E}-02$ & $5.4 \mathrm{E}+00$ \\
\hline High Income $(\%)$ & $-4.5 \mathrm{E}+00$ & $1.5 \mathrm{E}+00$ & $1.7 \mathrm{E}+00$ & $1.8 \mathrm{E}+00$ & $7.7 \mathrm{E}+00$ \\
\hline Accessibility Score & $-7.8 \mathrm{E}-01$ & $-2.8 \mathrm{E}-01$ & $3.3 \mathrm{E}-04$ & $5.7 \mathrm{E}-01$ & $1.1 \mathrm{E}+00$ \\
\hline \multicolumn{6}{|c|}{$\begin{array}{l}\text { Diagnostic information } \\
\text { Number of data points: 32,068 } \\
\text { Effective number of parameters: 192.2415 } \\
\text { Effective degrees of freedom: } 31,875.76 \\
\text { AICc: }-5,447.286 \\
\text { AIC: }-5,594.308 \\
\text { Residual sum of squares: } 1,569.958 \\
\text { R-square value: } 0.8458043 \\
\text { Adjusted } R \text {-square value: } 0.8448744\end{array}$} \\
\hline
\end{tabular}

Table 5: Distribution of coefficient values from the GWR model of variables to house prices

and accessibility effects - in which, larger spatial disparities at local levels are more evident than previously indicated in the OLS model. First, with respect to accessibility, the model's estimate coefficients indicate that, generally, improvements in accessibility garner a 3.3 per cent median increase in house prices. However, disaggregating these results spatially, the models shows a clear divide between the East and West regions of Greater Sydney. The most striking observation from these GWR results is the difference in direction and magnitude of the effect of accessibility across Greater Sydney. Generally, there is a negative relationship of prices with accessibility in the far Southeast and Northeast of Sydney, whilst there is a weak positive relationship in central Sydney. Further, in Western and outer Sydney, a stronger positive relationship is documented. These findings suggest that accessibility may not necessarily be an important determinant of house prices in all areas. There may be several possible explanations for this.

First, the higher attractiveness of homes in Sydney's more affluent suburbs (e.g. in Eastern suburbs) are appear to be more sensitive to locational attributes such as views, access to green-spaces and beaches, good schools, and larger houses compared with employment accessibility. Importantly, these afflu- 


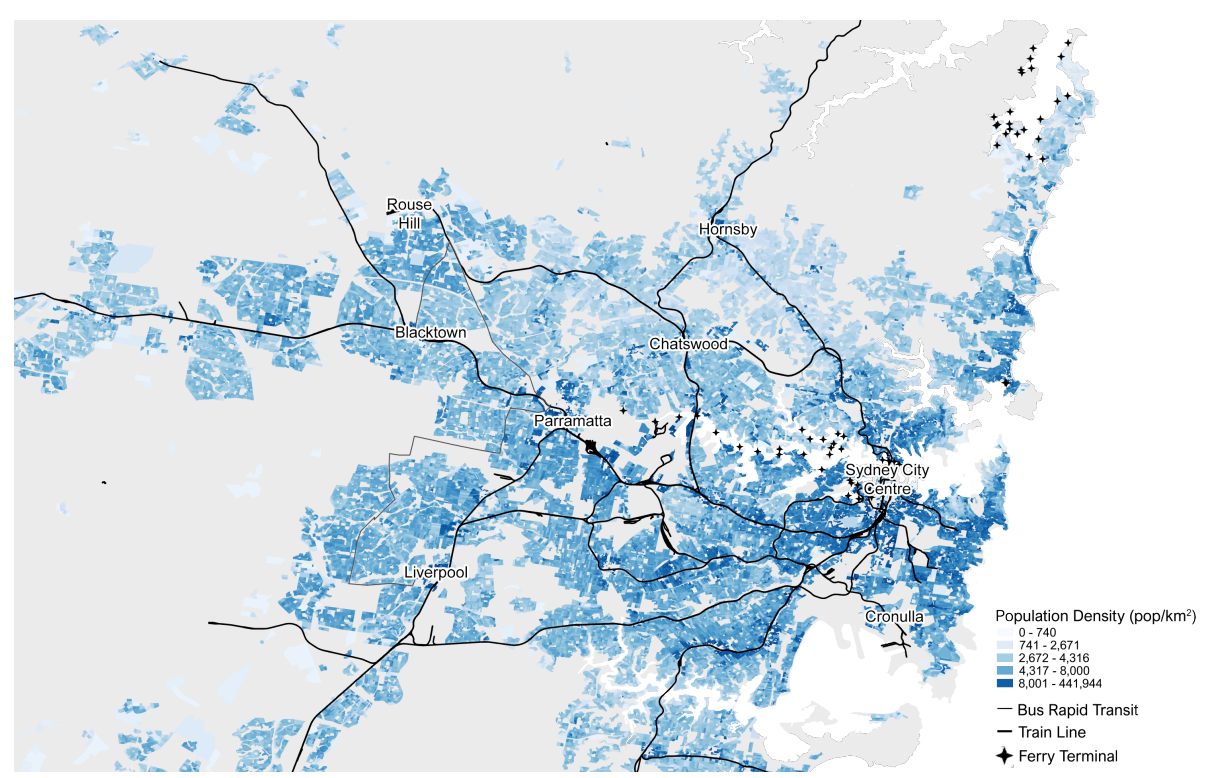

Figure 14: Major public transport lines and suburb population distribution in Sydney

ent suburbs are characterised by these better amenities compared with less prosperous suburbs (Bangura \& Lee 2019). In comparison, in more segregated areas in the outer Sydney suburbs, home choice becomes more utilitarian. In these areas, accessibility to employment becomes a more deciding factor in determining house prices. This is likely related to demographic differences seen between these areas. In wealthier areas of Sydney, accessibility based on journey to work may not be as important for wealthy retirees that have been shown to cluster these areas (e.g., Sutherland Shire, Hornsby-Warringah, and the Northern Beaches). Another issue may be the further anisotropic nature of Sydney's public transport network, resulting in travel times for subgroups of commuters that differ from the road network based accessibility used in this model. As shown in 14 , the Southeastern and Northeastern suburbs are relatively less served by rail lines or dedicated right-of-way bus services than other suburbs (in 2016 - prior to the opening of new light rail in the Southeast). This may mean that actual employment flows from the western suburbs are underestimated, and from the eastern suburbs are overestimated, in the accessibility model, which is based on road distances. This is a noted limitation of the current analysis with future work is required to incorporate public transport accessibility into the model. Notwithstanding, however, it is expected that the developed accessibility model is relevant for a majority of Sydney's residents given the city's 65.2 per cent reliance on cars for commuting (Australian Bureau of Statistics 2017).

Rather, a stronger determinant of house prices in these areas may be the variable income group stratum present. The GWR results indicate a median 
decrease of 0.28 per cent associated within increasing proportions of low-income earners; whereas, a median increase of 1.7 per cent is noted with properties found in predominantly high-income areas. However, it is interesting to note the coefficient changes in areas like Sydney's centre-east suburbs. In these relative higher priced areas, the GWR indicates that any small increase in low-income groups within the area has a much more detrimental effect on house prices than seen in the suburbs of Sydney's West and Inner West. The sensitivity of property values in these areas is indicative of the area's primacy. It suggests a level of income stratification in the area that is supported by raised house prices. Finally, whilst accessibility may not be the leading factor in determining property prices across Sydney, it is still considered a major factor in lowerincome areas as represented by the model's coefficients (ref. Figure 13). As such, it can be interpreted that spatial equity remains an issue in Sydney, whereby the distribution of employment accessibility does not cover those groups that most need and want this accessibility.

\section{Conclusion}

This paper examined how and to what extent accessibility are related to income segregation and house prices in the Greater Sydney Area. Several key findings have been identified. First, low-income groups tend to be more clustered together in Sydney, which has given rise to enclaves of low-social diversity. However, this distribution to be asymmetric with higher income groups in the city. Middle- and high- income earners tend to be evenly distributed throughout the city, with increased demographic mixing. Second, poor accessibility does not appear to be a major contributor the income segregation phenomenon in Sydney. Accessibility remains relatively equal between both high-income and low-income neighbourhoods given their proximity in Sydney. The results from this paper show that a relatively tenuous relationship between incomes and accessibility. In fact, in several areas, high income is accompanied by lowered accessibility. These findings suggest a level of self-isolation and lack of dependency on access to employment opportunities by higher-income residents. Lastly, it was also found that other individual property characteristics (e.g., the presence of views, access to better schools, and access to recreational amenities) in high income areas play a much larger role in deciding property values in these areas. This has been attributed to the dependency on personal vehicles and the lowered need for access to employment centres within the high-income stratum. This brings to light the main limitation of this study, where only road access is considered as a measure of distance. Whilst this transport modality pertains to approximately a third of Sydney's commuters, public transport nevertheless still plays an important role in contributing to property values by facilitating access to those predominantly residing in lower-income areas.

These findings have several profound implications on urban and housing policies. Specifically, policy makers should consider the issue of income segregation as low-income groups tend to be more segregated in their policies decision 
making. Further, an enhancement of accessibility is not a feasible solution to address income segregation effectively as this is not a main contributor to the onset of income segregation in Sydney. However, future study can consider further work to incorporate multi-modal transport is thus required to provide a more holistic view of this nexus in Sydney. Further research will also need to consider understanding accessibility not just to employment but accessibility to amenities and essential urban services as these are important consideration of the urban system.

\section{References}

ABS (2016), 'Census of population and housing destination zones, august 2016 .

URL: $\quad$ https://www.abs.gov.au/statistics/people/population/censuspopulation-and-housing-destination-zones/latest-release

ABS (2017), 'Total personal income (weekly) (incp)', Australian Bureau of Statistics.

URL: $\quad$ https://www.abs.gov.au/ausstats/abs@.nsf/Lookup/by Subject/2900.0 2016 Main Features INCP Total Personal Income (weekly) 10059

ACOSS (2016), 'Poverty in australia 2016', The Australian Council of Social Service pp. 1-41.

AGPC (2018), 'Rising inequality? a stocktake of the evidence', Productivity Commission Research Paper pp. 1-162.

Albuquerque, P. H. M., Medina, F. A. S. \& Silva, A. R. d. (2017), 'Geographically weighted logistic regression applied to credit scoring models', Revista Contabilidade $\& 3$ Finanças 28(73), 93-112.

Alesina, A., Baqir, R. \& Easterly, W. (1999), 'Public goods and ethnic divisions', The Quarterly Journal of Economics 114(4), 1243-1284.

Alesina, A. \& La Ferrara, E. (2000), 'Participation in heterogeneous communities', The Quarterly Journal of Economics 115(3), 847-904.

Arapoglou, V. P. \& Sayas, J. (2009), 'New facets of urban segregation in southern europe: Gender, migration and social class change in Athens', European Urban and Regional Studies 16(4), 345-362.

Åslund, O., Östh, J. \& Zenou, Y. (2010), 'How important is access to jobs? old question -improved answer', Journal of Economic Geography 10(3), 389-422.

Australian Bureau of Statistics (2017), 'Media release - more than two in three drive to work, census reveals (media release)'.

Bangura, M. \& Lee, C. L. (2019), 'The differential geography of housing affordability in sydney: a disaggregated approach', Australian Geographer 50(3), 295-313. 
Banister, D. (2005), Unsustainable transport: city transport in the new century, Routledge.

Bartholomew, K. \& Ewing, R. (2011), 'Hedonic price effects of pedestrian-and transit-oriented development', Journal of Planning Literature 26(1), 18-34.

Batty, M., Morphet, R., Masucci, P. \& Stanilov, K. (2014), 'Entropy, complexity, and spatial information', Journal of geographical systems 16(4), 363-385.

Brondeel, R., Weill, A., Thomas, F. \& Chaix, B. (2014), 'Use of healthcare services in the residence and workplace neighbourhood: the effect of spatial accessibility to healthcare services', Health \&3 place 30, 127-133.

Bruce, P., Bruce, A. \& Gedeck, P. (2020), Practical Statistics for Data Scientists: $50+$ Essential Concepts Using $R$ and Python, O'Reilly Media.

Cervero, R., Rood, T. \& Appleyard, B. (1995), 'Job accessibility as a performance indicator: An analysis of trends and their social policy implications in the san francisco bay area'.

Cervero, R. et al. (1997), 'Paradigm shift: from automobility to accessibility planning', Urban Futures (Canberra) (22), 9.

Charles, C. Z. (2003), 'The dynamics of racial residential segregation', Annual Review of Sociology 29(1), 167-207.

Cheng, J. \& Bertolini, L. (2013), 'Measuring urban job accessibility with distance decay, competition and diversity', Journal of Transport Geography 30, 100-109.

Curl, A., Nelson, J. D. \& Anable, J. (2011), 'Does accessibility planning address what matters? a review of current practice and practitioner perspectives', Research in Transportation Business $\&$ Management 2, 3-11.

Cutler, D. M. \& Glaeser, E. L. (1997), 'Are ghettos good or bad?', The Quarterly Journal of Economics 112(3), 827-872.

Davidson, K. B. (1995), Accessibility and isolation in transport network evaluation, in 'Proceedings of the VII World Conference on Transport Research', The University of South Wales Sidney, pp. 8-10.

Davidson, P., Saunders, P. \& Phillips, J. (2018), 'Inequality in australia 2018', Strawberry Hills, NSW: ACOSS and UNSW Sydney .

De Bruyne, K. \& Van Hove, J. (2013), 'Explaining the spatial variation in housing prices: an economic geography approach', Applied Economics 45(13), 1673-1689.

Dennett, A. (2012), 'Estimating flows between geographical locations:'get me started in'spatial interaction modelling', Technical report . 
Dujardin, C. \& Goffette-Nagot, F. (2005), 'Neighborhood effects, public housing and unemployment in france'.

Ewing, R. H., Pendall, R. \& Chen, D. D. (2002), Measuring sprawl and its impact, Vol. 1, Smart Growth America Washington, DC.

Ewing, R., Hamidi, S., Grace, J. B. \& Wei, Y. D. (2016), 'Does urban sprawl hold down upward mobility?', Landscape and Urban Planning 148, 80-88.

Fábián, Z. et al. (2014), 'Method of the geographically weighted regression and an example for its application', Regional Statistics (01), 61-75.

Fan, Y. (2012), 'The planners' war against spatial mismatch: Lessons learned and ways forward', Journal of Planning Literature 27(2), 153-169.

Farrington, J. H. (2007), 'The new narrative of accessibility: its potential contribution to discourses in (transport) geography', Journal of Transport Geography 15(5), 319-330.

Ferrer, A. L. C., Thomé, A. M. T. \& Scavarda, A. J. (2018), 'Sustainable urban infrastructure: A review', Resources, Conservation and Recycling 128, 360372 .

Fischer, M. J. (2003), 'The relative importance of income and race in determining residential outcomes in us urban areas, 1970-2000', Urban Affairs Review 38(5), 669-696.

Fotheringham, A. S., Brunsdon, C. \& Charlton, M. (2003), Geographically weighted regression: the analysis of spatially varying relationships, John Wiley \& Sons.

Fotheringham, A. S. \& Oshan, T. M. (2016), 'Geographically weighted regression and multicollinearity: dispelling the myth', Journal of Geographical Systems 18(4), 303-329.

Gareth, J., Daniela, W., Trevor, H. \& Robert, T. (2013), An introduction to statistical learning: with applications in $R$, Spinger.

Geurs, K. T., De Montis, A. \& Reggiani, A. (2015), 'Recent advances and applications in accessibility modelling', Computers, environment and urban systems $49,82-85$.

Geurs, K. T., Krizek, K. J. \& Reggiani, A. (2012), Accessibility analysis and transport planning: challenges for Europe and North America, Edward Elgar Publishing.

Geurs, K. T. \& Van Wee, B. (2004), 'Accessibility evaluation of land-use and transport strategies: review and research directions', Journal of Transport geography 12(2), 127-140. 
Gittins, R. (2018), 'Inequality: Nothing to see here is not the true picture', The Sydney Morning Herald.

URL: https://www.smh.com.au/business/the-economy/inequality-nothingto-see-here-is-not-the-true-picture-20180831-p500ww.html

Giuliano, G. \& Small, K. A. (1993), 'Is the journey to work explained by urban structure?', Urban studies 30(9), 1485-1500.

Gobillon, L., Selod, H. \& Zenou, Y. (2007), 'The mechanisms of spatial mismatch', Urban studies 44(12), 2401-2427.

Hansen, W. G. (1959), 'How accessibility shapes land use', Journal of the American Institute of planners 25(2), 73-76.

Hernández-Murillo, R. \& Owyang, M. T. (2006), 'The information content of regional employment data for forecasting aggregate conditions', Economics Letters 90(3), 335-339.

Hillier, A. E. (2003), 'Spatial analysis of historical redlining: a methodological exploration', Journal of Housing Research pp. 137-167.

Ihlanfeldt, K. (1994), 'The spatial mismatch between jobs and residential locations within urban areas', Cityscape 1(1), 219-244.

Kain, J. F. (1992), 'The spatial mismatch hypothesis: three decades later', Housing policy debate 3(2), 371-460.

Kantorovich, Y. G. (1992), 'Equilibrium models of spatial interaction with locational-capacity constraints', Environment and Planning A 24(8), 10771095.

Kneebone, E. \& Holmes, N. (2015), 'The growing distance between people and jobs in metropolitan America', The Brookings Institution, March .

Lee, C. L., Piracha, A. \& Fan, Y. (2018), 'Another tale of two cities: access to jobs divides sydney along the'latte line", The Conversation .

Li, H., Campbell, H. \& Fernandez, S. (2013), 'Residential segregation, spatial mismatch and economic growth across US metropolitan areas', Urban Studies 50(13), 2642-2660.

Lieske, S. N., van den Nouwelant, R., Han, J. H. \& Pettit, C. (2021), 'A novel hedonic price modelling approach for estimating the impact of transportation infrastructure on property prices', Urban Studies 58(1), 182-202.

Luo, J. (2014), 'Integrating the Huff model and floating catchment area methods to analyze spatial access to healthcare services', Transactions in GIS 18(3), 436-448.

Määttänen, N. \& Terviö, M. (2014), 'Income distribution and housing prices: An assignment model approach', Journal of Economic Theory 151, 381-410. 
Massey, D. S. \& Denton, N. A. (1988), 'The dimensions of residential segregation', Social forces $\mathbf{6 7}(2), 281-315$.

Masucci, A. P., Serras, J., Johansson, A. \& Batty, M. (2013), 'Gravity versus radiation models: On the importance of scale and heterogeneity in commuting flows', Physical Review E 88(2), 022812.

Miller, E. J. (2018), 'Accessibility: measurement and application in transportation planning'.

Mulley, C. (2014), 'Accessibility and residential land value uplift: Identifying spatial variations in the accessibility impacts of a bus transitway', Urban Studies 51(8), 1707-1724.

Muraco, W. A. (1972), 'Intraurban Accessibility', Economic Geography 48(4), 388-405.

Nelson, A. C. \& Moore, T. (1993), 'Assessing urban growth management: The case of Portland, Oregon, the usa's largest urban growth boundary', Land Use Policy 10(4), 293-302.

Ohnishi, T., Mizuno, T., Shimizu, C. \& Watanabe, T. (2011), 'On the evolution of the house price distribution'.

Oshan, T., Wolf, L. J., Fotheringham, A. S., Kang, W., Li, Z. \& Yu, H. (2019), 'A comment on geographically weighted regression with parameter-specific distance metrics', International Journal of Geographical Information Science 33(7), 1289-1299.

Páez, A., Scott, D. M. \& Morency, C. (2012), 'Measuring accessibility: positive and normative implementations of various accessibility indicators', Journal of Transport Geography 25, 141-153.

PCA (2019), 'Treasury laws amendment (medicare levy and medicare levy surcharge) bill 2019', The Parliament of the Commonwealth of Australia p. 1-17.

Pettit, C., Shi, Y., Han, H., Rittenbruch, M., Foth, M., Lieske, S., Van De Nouwelant, R., Mitchell, P., Leao, S., Christensen, B. et al. (2020), 'A new toolkit for land value analysis and scenario planning', Environment and Planning B: Urban Analytics and City Science p. 2399808320924678.

Piovani, D., Arcaute, E., Uchoa, G., Wilson, A. \& Batty, M. (2018), 'Measuring accessibility using gravity and radiation models', Royal Society open science $\mathbf{5}(9), 171668$.

Proffitt, D. G., Bartholomew, K., Ewing, R. \& Miller, H. J. (2019), 'Accessibility planning in american metropolitan areas: Are we there yet?', Urban Studies 56(1), 167-192. 
Sá, C., Florax, R. J. \& Rietveld, P. (2006), 'Does accessibility to higher education matter? choice behaviour of high school graduates in the netherlands', Spatial Economic Analysis 1(2), 155-174.

Sánchez, F. J., Liu, W. M., Leathers, L., Goins, J. \& Vilain, E. (2011), 'The subjective experience of social class and upward mobility among African American men in graduate school.', Psychology of Men \&3 Masculinity 12(4), 368.

Sila, U. \& Dugain, V. (2019), 'Income, wealth and earnings inequality in australia: Evidence from the hilda survey'.

Stoll, M. A. (1999), 'Spatial job search, spatial mismatch, and the employment and wages of racial and ethnic groups in los angeles', Journal of Urban Economics 46(1), 129-155.

Tan, Y. \& Wu, C.-f. (2003), 'The laws of the information entropy values of land use composition', Journal of natural resources 18(1), 112-117.

Topf, J. (2009).

Tsou, K.-W., Hung, Y.-T. \& Chang, Y.-L. (2005), 'An accessibility-based integrated measure of relative spatial equity in urban public facilities', Cities 22(6), 424-435.

Turner, M. A., Popkin, S. J. \& Rawlings, L. (2009), Public housing and the legacy of segregation, The Urban Insitute.

Van Eck, J. R. \& de Jong, T. (1999), 'Accessibility analysis and spatial competition effects in the context of GIS-supported service location planning', Computers, Environment and Urban Systems 23(2), 75-89.

Vickerman, R. W. (1974), 'Accessibility, attraction, and potential: a review of some concepts and their use in determining mobility', Environment and Planning A 6(6), 675-691.

Wasmer, E. \& Zenou, Y. (2002), 'Does city structure affect job search and welfare?', Journal of urban Economics 51(3), 515-541.

Wiesel, I., Ralston, L. \& Stone, W. (2020), 'How the housing boom has driven rising inequality', The Conversation .

URL: https://theconversation.com/how-the-housing-boom-has-driven-risinginequality-102581

Wilson, A. (2013), Entropy in Urban and Regional Modelling (Routledge Revivals), Routledge.

Wilson, A. G. (1971), 'A family of spatial interaction models, and associated developments', Environment and Planning A 3(1), 1-32.

Yang, R., Liu, Y., Liu, Y., Liu, H. \& Gan, W. (2019), 'Comprehensive public transport service accessibility index - a new approach based on degree centrality and gravity model', Sustainability 11(20), 5634 . 